\title{
MONETARY POLICY, NOMINAL INTEREST RATES, AND LONG-HORIZON INFLATION UNCERTAINTY
}

\author{
Stephen Wright
}

27 October 1998

\author{
Faculty of Economics and Politics \\ University of Cambridge \\ Sidgwick Avenue \\ Cambridge CB3 9DD
}

Tel (01223) 335234

Fax (01223) 335475

E-Mail: stephen.wright@econ.cam.ac.uk

\begin{abstract}
Empirical evidence presented in this paper shows that the predictability of inflation at long horizons varies considerably across countries. Both simple theory and empirical evidence suggest that the crucial factor is the extent to which systematic monetary policy succeeds in stabilising the incipient unit root in inflation. The mechanism by which it does this appears however to be complicated by strong empirical evidence that nominal interest rates have real effects, which implies that monetary policy need not be so vigorous in reactions to inflation. This helps to explain why inflation rates in the US and (especially) Germany have been relatively predictable, despite monetary policy rules which appear to have been barely stabilising. The paper also presents tentative evidence that the power of nominal interest rate effects is inversely related to long-horizon inflation uncertainty, and hence ultimately uncertainty about monetary policy.
\end{abstract}

JEL Classifications: C32, E31, E50, E52

Keywords: Monetary Policy, Nominal Interest Rates, Inflation Uncertainty.

(Also available as DAE Working Paper no. 9820)

I am very grateful for valuable comments from Willem Buiter, Peter Spencer, Charles Goodhart, and participants in seminars at Exeter University, Birkbeck College London, Yale, the Boston Fed, the Federal Reserve, the International Monetary Fund, and the 1997 Royal Economic Society and Money, Macro and Finance Conferences. 
Empirical evidence presented in this paper shows that the predictability of inflation at long horizons varies considerably across countries, in a way that is uncorrelated with short-run uncertainty. Both simple theory and empirical evidence suggest that long-horizon inflation uncertainty is uncertainty about monetary policy.

There is a well-known link between monetary policy and the persistence of inflation (eg Alogoskoufis \& Smith(1991)); but the impact on inflation uncertainty has received less attention. A fairly range of sticky price/vertical Phillips Curve representations of the inflation processes ( $e g$ those of Taylor (1980) and Fuhrer \& Moore (1995a)), imply an incipient unit root in inflation, which, if not suppressed, will imply that inflation uncertainty increases without limit as the forecast horizon increases. The most crucial thing for monetary policy to do is to suppress this unit root; but, more generally, the nature of systematic monetary policy will determine the degree of long-horizon inflation uncertainty.

The framework in which this paper works is in line with a growing body of research which has, effectively, revived the once deeply unfashionable idea of stabilisation policy as a feasible objective (eg, Svensson(1997), Ball (1997), Batini \& Haldane (1998), Clarida, Gali \&Gertler(1998)). In this literature, it is common to represent optimal monetary policy in terms of of a loss function which has, almost without comment, "shifted moments" from the Samuelson/Barro-Gordon loss function, which had mean inflation and mean output as arguments, to one in terms of the variances of output and inflation. This shift has been characterised by Taylor (1994) as a response to two of the primary critiques of the stabilisation theories of the 1960s - the vertical Phillips Curve constraint, and the rules vs discretion problems that arise from targeting output levels which ignore this constraint. The "New Stabilisation Theory" essentially takes both of these critiques as given, along with the separation of powers between fiscal and monetary policy which arises therefrom. The monetary authority under consideration, therefore, has a feasible objective - variance reduction - which it pursues with a single instrument.

The welfare foundations of a loss function in inflation and output variances remain unclear, although a combination of risk aversion, imperfect capital markets and sticky prices make it plausible to assume that the representative agent will dislike both inflation and output uncertainty. But it does 
seem clear that the nature of the market imperfections will affect the nature of the objective. Price, and possibly inflation stickiness ${ }^{1}$ are likely to increase output variance, and imperfect capital markets may make it hard either to hedge the impacts of this variability, or smooth consumption optimally. There may therefore be sound reasons why monetary policy might in principle take an interest in short-run output variance reduction.

In contrast, there may be equally sound reasons why monetary policy should primarily be inerested in inflation variance reduction over long horizons. Sticky prices mean that inflation variance is, over short horizons, almost definitionally small - at least in relation to output variance; and monetary policy will be able to impact upon it to a very limited extent, if at all. Over long horizons, however, the reverse may be (and empirically often has been) the case. A very large number of financial decisions are taken over very long horizons. Where contracts are imperfectly indexed, ${ }^{2}$ the expected utility of risk-averse agents will depend on the predictability of the inflation rate over the relevant horizon - and hence on monetary policy.

Another aspect of the "New Stabilisation Theory" literature which is now increasingly taken for granted (even if perceptions of this change have not travelled much further than the confines of this literature itself), is that the single instrument of monetary policy is not money, but the nominal interest rate. Academic economists have arguably been rather slow to catch up on what central bankers have practised (if not always preached) for decades; but the empirical evidence for the nominal interest rate as the instrument of monetary policy has mounted in recent years $(e g$, Bernanke \& Blinder (1992), Taylor (1993), Bernanke \& Mihov (1997), Clarida \& Gertler (1997), Clarida, Gali \& Gertler (1998)). In one sense this shift is trivial: for any assumed interest rate reaction function there must exist in principle an equivalent money supply function, and vice versa. But macroeconomists have not quite got used to the implications of this shift, nor of the empirical evidence as to the way the nominal interest rate impacts on the economy. The shift complicates matters in two ways.

${ }^{1}$ There is now a vast literature which attempts to rationalise the empirical phenomon of sticky prices; rather less attention has been paid to the observed stickiness of inflation (but see Fuhrer \& Moore, 1995a; Roberts, 1997)

${ }^{2}$ Full indexation could only be obtained in two of the countries examined in this paper (the United Kingdom and Canada) and only in the latter part of the historical period I examine. 
The first is fairly familiar, although rarely spelled out explicitly. The great attraction of the textbook fixed money supply model is that it is independent of parameter values. Once we move to a nominal interest rate rule, it is clear-cut, and fairly well-known, that the parameters in the rule are crucial. In the context of the simple model of this paper, the coefficient on inflation in a generalised "Taylor Rule" representation of interest rate setting is the crucial determinant of inflation uncertainty.

The second complication is in the way the nominal interest rate impacts upon the economy. The empirical evidence in this paper brings out a feature implicit in much other research, but little commented on $^{3}$, that the impact of the nominal interest rate on the real economy appears to violate a central assumption on the transmission mechanism of monetary policy. Except in the crudest textbook model, it is usual to assume that, even if monetary policy operates via the nominal interest rate, it works only by changing real interest rates. The empirical evidence of this paper brings out clearly what was implicit in earlier research: that in fact the crude textbook model is closer to reality. The implication of this phenomenon is that monetary policy need not be so vigorous in reactions to inflation as it would need to be if the economy were entirely "real". This is an important factor in explaining why postwar inflation rates in the US and (especially) Germany have been relatively predictable, despite monetary policy rules which might appear to have been barely stabilising.

There is however some evidence that the impact of nominal interest rates on the real economy is not independent of monetary policy itself. Nominal interest rates can only impact on the real economy (or possibly, in Fuhrer \& Moore's (1995b) rationalisation, appear to impact on the real economy) if inflation is a stationary process - and this in turn ultimately depends on the nature of the monetary rule. The final section of this paper also presents tentative evidence that the power of nominal interest rate effects is inversely related to long-horizon inflation uncertainty, and hence ultimately uncertainty about monetary policy.

The paper is structured as follows. Section II presents a simple measure of long-horizon inflation uncertainty for a range of OECD countries. Whilst standard tests for a unit root give familiarly ambiguous results; the proposed new measure summarises much more clearly the the very different experiences in the sample of countries shown. In some countries (most obviously Germany and Switzerland), inflation has been fairly easy to predict over long horizons; in many others, even when

${ }^{3}$ An important exception is Fuhrer \& Moore (1995b). 
the evidence for or against a unit root is ambiguous, the range of uncertainty with respect to future inflation has been very much greater. Such uncertainty appears, however, uncorrelated with the degree of unprectability of inflation in the short term.

Section III presents a simple analytical framework which examines the impact of monetary policy on long-horizon inflation uncertainty. A fairly general sticky price representation, which nests a number of standard models, leads to a common feature that all can be represented as versions of the long-run vertical Phillips Curve, which in turn implies an incipient unit root in inflation. Monetary policy is assumed to follow a systematic rule for the nominal interest rate which is a generalised version of the "Taylor Rule". A single parameter in this rule (the long-run response of the nominal interest rate to the inflation rate) will determine whether or not the unit root in inflation is eliminated. In an economy which is otherwise entirely "real", the requirement is simply that real interest rates respond positively to deviations of the inflation rate from target (a property which was present in the original specification in Taylor (1993)) - ie that this parameter be greater than unity. More generally, the magnitude of this parameter will be the key determinant of long-horizon inflation uncertainty.

The picture is complicated somewhat if nominal, as opposed to real interest rates impact on real activity, as a number of previous empirical studies have suggested ${ }^{4}$ - in this situation, the same parameter in the "Taylor Rule" is still crucial, but the response of interest rates to inflation need not be so vigorous - indeed it may be that (backward-looking) real interest rates may fall in response to an inflation shock, but will still stabilise inflation.

Section III concludes with a brief analysis of the implications of different choices of the critical parameter for a simple adhoc loss function. There is a clear, and very marked nonlinearity of the loss function close to the value associated with a unit root in inflation.

Section IV presents results for three countries, the United States, Germany and the United Kingdom, derived from an empirical representation of the simple model of Section III. Whilst the Vertical Phillips Curve appears to be consistent with data for all three countries, the systematic element in monetary policy has differed in important respects, which appear broadly consistent with the very different degrees of long-horizon inflation uncertainty. However, even in Germany, the most

${ }^{4}$ Most notably, Bernanke \& Blinder (1992), Fuhrer \& Moore (1995b). 
obviously anti-inflationary of the three countries, the crucial parameter in the Taylor Rule has not been significantly different from unity. The fact that the Bundesbank has nonetheless succeeded in making German inflation so predictable at long horizons can be attributed to a marked tendency (common to some extent to all three countries examined) for the real economy to respond to the nominal, rather than real interest rate.

Section V looks further at the link between this phenomenon and inflation uncertainty, and hence in turn with monetary policy. The nominal rate can only affect real activity if monetary policy achieves the aim of rendering inflation stationary, or nearly so. Therefore, if systematic monetary policy, operating via the nominal interest rate, succeeds in this aim, it may simultaneously increase the impact of the nominal interest rate itself on the real economy. Section V presents additional cross-sectional evidence which appears to support the hypothesis that lower levels of long-horizon inflation uncertainty are associated with a more significant impact of nominal interest rates on activity. Thus, whilst the nominal interest rate effect complicates the picture, inflation uncertainty does seem to depend ultimately on uncertainty about monetary policy.

Section VI concludes the paper, and draws out some of its main implications. 


\section{LONG-HORIZON INFLATION UNCERTAINTY: AN INTERNATIONAL COMPARISON}

Consider Figure 1, which shows CPI inflation in 13 OECD countries from the early 1960s onwards.

Certain key features appear to stand out:

(i) All countries shown appear to start the period at very similar inflation rates, and to end at rates which are even more similar. ${ }^{5}$ One interpretation of this feature is that, over long enough time periods, policy preferences in terms of desired inflation are not too different either over time, or across a quite wide range of countries at a comparable level of development.

(ii) There appears to be evidence of some common factors driving inflation in all the countries shown. All were hit by upward shocks to inflation at similar times in the early and late 1970s, and downward shocks in the mid-1980s. This is of course unsurprising given what we know about the history of oil and other commodity prices.

(iii) Whilst the impulses were similar in all countries, the responses of inflation were very different. In two countries, Switzerland and Germany, inflation stayed within quite narrow bounds (never hitting double figures in the latter country), whilst in other countries, the initial impulse appears to have been magnified considerably.

As a result of these very different responses, it is clear that long-horizon inflation uncertainty has differed considerably between the different countries. There is no clear consensus, however, on how these differences can be characterised in qualitative terms.

${ }^{5}$ The similarity at the start of the period is affected by, but is not just a function of the Bretton Woods arrangements. Persistent inflation differentials could and did exist throughout the Bretton Woods period (albeit on a more modest scale than in the period of flexible rates) reflecting both real exchange rate changes, and periodic devaluations. The latter gave countries scope, in principle, to choose inflation rates which were reasonably different from the the other members of the regime, without any necessary implications for real exchange rates. Some, but relatively few countries exploited this potential, eg:

\begin{tabular}{|l|l|l|l|l|}
\hline \multicolumn{6}{|l|}{ Rates of Devaluation against US Dollar at Average Annual Rate, 1948-1970 } \\
\hline Spain & France & UK & Turkey & Denmark \\
\hline $4.3 \%$ & $3.4 \%$ & $2.4 \%$ & $7.7 \%$ & $2.0 \%$ \\
\hline
\end{tabular}


Empirical researchers have been roughly evenly divided between those who assume that inflation is a unit root process (eg Evans \& Wachtel(1993), Ball \& Cecchetti(1990)), and hence implicitly reject conclusion (i), and others ((eg Bernanke \& Blinder, 1992; Fuhrer \& Moore 1995a, 1995b; Gertler et al, 1997)) who assume it is a stationary process. If it were possible to obtain clear-cut evidence for or against a unit root in inflation in any given country, this would have potentially crucial implications for long-horizon inflation uncertainty. A series which is stationary has a variance which tends to a finite limit as the forecast horizon tends to infinity; in contrast if a series contains a unit root its variance increases without limit with the forecast horizon. However the evidence in either direction on this score is ambiguous.

The bottom panel of Figure 2 shows, for the same 13 OECD countries, the most commonly used test statistic, the augmented Dickey-Fuller (ADF) statistic testing the null of a unit root in the CPI inflation rate. ${ }^{6}$ Almost all the statistics shown are in a range in which the null cannot be rejected conclusively; but equally, it is well known that such tests have very low power against the alternative of a stationary, but slowly adjusting process (De Jong et al, 1989), hence the statistics are of limited information value.

As an indicator of relative inflation uncertainty - $i e$ of whether one country's inflation rate is more unpredictable than another's - the ADF test is also of little value. It is certainly somewhat surprising that two countries with inflationary experiences as diverse as Italy and Germany should generate such similar test results. However there is an alternative method of comparison, which avoids the need to come to a clear conclusion on the unit root issue, and which also brings out considerably more marked contrasts between different countries. This approach attempts to quantify differences in the degree of predictability of inflation over long horizons, even when stationarity is taken as given.

Let the time series for inflation, $\pi_{\mathrm{t}}$ be given the standard univariate representation:

$$
\Delta \pi_{t}=\alpha_{0}+\alpha_{1} \pi_{t-1}+\beta(L) \Delta \pi_{t-1}+\epsilon_{t}
$$

The ADF statistic is simply a test of the statistical significance of $\alpha_{1}$. Assuming stationarity, the infinite horizon forecast of inflation, $\bar{\pi}$, is given by $-\alpha_{0} / \alpha_{1}$. Given the properties of ordinary least

${ }^{6}$ Data sources and descriptions, and a description of estimation procedures are given in the appendix. 
squares these values, which might be called "steady-state" inflation rates, differ very little from historic averages. Of more interest, however, are the (asymptotic) 95\% confidence intervals for these steady-state values, ${ }^{7}$ which vary much more markedly, and arguably more informatively, than do the ADF statistics. These are shown in the top panel of Figure 2.

In only two countries, Germany and Switzerland, does "steady-state" inflation appear to be reasonably well-identified, with $95 \%$ confidence bands only just over a percentage point either side. Moving across the chart to the right, the figures are ranked in order of the width of the confidence interval. The degree of uncertainty increases very rapidly. It is easy to see that there is a reasonable degree of association between high levels of "steady-state" inflation (ie the mid-points of the two figures shown), and the degree of uncertainty associated with these values (as might be expected given the well-known link between means and unconditional variances of inflation rates). But the correlation is by no means perfect. Thus Japan has a relatively low steady-state inflation rate, but this rate is distinctly less well-identified than that of the United States.

For most of the countries to the right of this point, the very concept of "steady-state" inflation appears to have little content in economic terms, irrespective of the nature of the evidence against a unit root, as given by the ADF test statistics. ${ }^{8}$ Inflation in these countries has thus been highly unpredictable at long horizons.

${ }^{7}$ Strictly speaking these are confidence intervals for the average inflation rate over an infinite horizon. As the forecast horizon tends to infinity, the variance of the average inflation rate over that horizon goes to a limiting value which is determined solely, as here, by parameter uncertainty. Note that this approach to longhorizon inflation uncertainty is very similar to that originally proposed by Klein(1975), although in that case the measure was derived over long, but finite horizons.

${ }^{8}$ Although the confidence intervals are clearly, by construction, related to the value of the ADF test statistic. The asymptotic variance approximation from which the confidence intervals are derived can be expressed in the form:

$$
\operatorname{var}(\bar{\pi}) \simeq \bar{\pi}^{2}\left[\left(\frac{\sigma_{0}}{\alpha_{0}}\right)^{2}+\left(\frac{\sigma_{1}}{\alpha_{1}}\right)^{2}-2\left(\frac{\sigma_{01}}{\alpha_{0} \alpha_{1}}\right)\right]
$$

where $\sigma_{0}$ and $\sigma_{1}$ are the variances of $\alpha_{0}$ and $\alpha_{1}$, and $\sigma_{01}$ their covariance. The second of the terms within the square brackets is equal to $\mathrm{ADF}^{-2}$. But the remaining terms appear also to be be empirically important. Note that, if there is actually a unit root in inflation, these confidence intervals will of course be infinite at an infinite forecast horizon. But in finite samples estimates of the autoregressive coefficient will tend to be biased downwards (Grubb \& Symons, 1985), and hence the absolute value of $\alpha_{1}$ will be biased upwards. Therefore, as the true value of $\alpha_{1}$ tends towards zero, the estimated long-horizon variance will be biased downwards to an increasing extent. Thus the confidence intervals shown in Figure 2 can probably be viewed as providing lower bounds for long-horizon inflation uncertainty. 
Figure 3 demonstrates that there has been no clear link between long-horizon inflation uncertainty and the degree of unpredictability of inflation in the short run (as captured by the width of the confidence interval in predicting inflation one quarter ahead). In all countries inflation is, as expected, more unpredictable in the long run than in the short run (all points lie above the 45 degree line); but the degree of long-run unpredictability is not obviously related to the degree of short-run unpredictability. ${ }^{9}$

\section{LONG-HORIZON INFLATION UNCERTAINTY: SOME SIMPLE ANALYTICS}

\section{(i) A Simple Model}

What explains the fact that some countries appear to have markedly more long-horizon inflation uncertainty than others? Monetary policy clearly plays a key role in the explanation, but the link is not as straightforward as might appear.

In the simple textbook model monetary policy is simply the provision of an an exogenously determined nominal stock of outside money. If the money stock is held fixed, the long horizon predictability of inflation in such a world must therefore be given by the long horizon predictability of output, which is normally taken as exogenous. Any additional uncertainty must stem from (exogenous) shocks to the money supply or velocity.

But a growing strand in modern analysis of monetary policy either endogenises the money stock in a reaction function, or simply replaces a money rule with a reaction function for the nominal interest rate. ${ }^{10}$ In such models, the degree of predictability of the long horizon inflation rate will depend on the nature of the monetary policy rule .

${ }^{9}$ There is a very weak positive association, with a squared correlation coefficient of 0.12 .

${ }^{10} E g$ Fuhrer \& Moore (1995b), Svensson(1997), Ball (1997), Batini \& Haldane (1998), Clarida, Gali $\&$ Gertler(1998). It is notable that even in some papers which explicitly model money demand, such as those of McCallum \& Nelson(1997) and Batini \& Haldane (op cit), this part of the model is rendered redundant by the inclusion of a separate interest rate reaction function. 
A simple log-linear analytical model can be used for illustrative purposes. Let short-term interest rates be set by a monetary policy reaction function which is, essentially, a generalised version of the "Taylor Rule". 11

$$
i_{t+1}=\tau(L) \pi_{t+1}^{e}+\sigma(L) y_{t+1}^{e}+u_{t+1}
$$

where $i_{t+1}$, the short-term nominal interest rate set at the start of period $t+1$, given information in period $t$, can be represented as the sum of the lag polynomial function $\tau(L)$ in expectations of inflation, $\pi$, (measured relative to some target rate of inflation) and $\sigma(L)$ in expectations of output, $y$ (measured relative to trend, or capacity output). Expected values are defined, for any variable $x$, by $x_{t+i}^{e} \equiv \mathrm{E}_{\mathrm{t}}\left(x_{t+i} \mid \Omega_{t}\right)$ (hence, for $\left.i \leq 0, x_{t+i}^{e}=x_{t+i}\right)$, hence expectational errors are white noise

Long-run responses are given by $\tau(\equiv \tau(1))$ and $\sigma(\equiv \sigma(1))$. In principle both polynomials may include only lags (as in the original specification, in which $\tau(\mathrm{L})=\tau \mathrm{L} ; \sigma(\mathrm{L})=\sigma \mathrm{L}$ ); or only leads (a pure forward-looking rule); or some combination of the two (as in, for example, Clarida et al (op cit)) in which forward-looking behaviour is tempered with some desire for instrument smoothing.

The representation of systematic monetary policy as an interest rate reaction function is, as noted above, non-crucial, since any such specification has an equivalent representation as a money supply function. In that alternative form, the crucial characteristic of the "Taylor Rule" is that the implied money supply function has a unit coefficient on the price level, implying full accommodation of price level shocks. This assumption is strongly supported by the data, which in no country can reject the null of a unit root in the price level, as opposed to the inflation rate. There are additionally, growing numbers of empirical studies which suggest that this is the way monetary policy is actually implemented in a range of developed economies,(see, for example, Bernanke \& Blinder,1992; Clarida \& Gertler, 1997; Clarida et al, 1997; Bernanke \& Mihov, 1997).

\footnotetext{
${ }^{11}$ Although the use of this term has now become common currency, it is perhaps worth noting that in its original form (Taylor, 1993) the Taylor rule was intended to summarise, in a simple form, interest rate reaction functions which had been in use in empirical macro models for some time previously. For an early example, see Fair(1979).
} 
Aggregate demand and inflation are assumed to be represented by the following reduced form equations:

$$
\begin{gathered}
y_{t}=-\lambda\left(i_{t}-\pi_{t}^{e}\right)-\mu i_{t}+d_{t} \\
\pi_{t}=\epsilon(L) \pi^{e}{ }_{t}+\alpha\left(y_{t}-s_{t}\right) ; \epsilon(1)=1 ; \quad \epsilon(0)=0
\end{gathered}
$$

Aggregate demand responds negatively to the expected real interest rate due to standard intertemporal substitution by consumers, and rate of return effects on investment. In addition, however the specification allows for the possibility that aggregate demand may also respond negatively to the nominal, as opposed to the expected real interest rate (an extreme example of such a specification is of course the textbook IS curve, which usually sets $\lambda$ to zero). This apparently $a d$ hoc assumption has a number of possible defences. The first is simply empirical: a wide range of past econometric studies have found significant nominal interest rate effects on both elements of demand, and on output (eg, Blinder \& Deaton (1985), Bernanke \& Blinder (1992), Clarida \& Gertler (1997), Fuhrer and Moore (1995b)). A second (proposed by Fuhrer and Moore (op cit)) assumes that demand responds to an expected long-term real rate, the time series properties of which resemble the nominal short rate. ${ }^{12}$ A third possible rationale would be in terms of credit market imperfections, if long-term financial contracts are specified in nominal terms, and individuals have restricted access to new finance. ${ }^{13}$ A final justification is perhaps the most straightforward: since standard theory would predict that nominal rates should not impact on output, the implied restriction (ie, that $\mu=0$ ) is easily testable empirically.

Equation (3) represents inflation as a generalised long-run vertical Phillips Curve process. ${ }^{14}$ The lag polynomial function $\epsilon(\mathrm{L})$ may again in principle include both leads and lags. The specification

\footnotetext{
${ }^{12}$ This argument depends crucially on the assumption that monetary policy succeeds in rendering the inflation rate stationary - an issue discussed further below.

${ }^{13} \mathrm{~A}$ rationale for this assumption can be sketched as follows. Suppose there is a proportion $\kappa$ of liquidity-constrained consumers, whose consumption is equal to their disposable income, $Y_{d}$, which in turn is defined in levels by $Y_{d}=W . L-i . D$, where W.L is labour income, $i$ is the nominal interest rate, and $D$ is inherited net debt. If this were the only source of nominal interest rate effects, log-linearising, $\mu$ would be approximately equal to $\kappa D / Y_{d}$. Whilst I am unaware of any formal model of this form of nominal rigidity, it is implicit in much discussion of the "credit channel" of monetary policy ( $e g$ the heuristic analysis of Bernanke \& Gertler (1995)), as well as in the internal workings of many empirical macro-models.
}

${ }^{14}$ Where the term "Phillips Curve" is taken to represent any reduced form representation of the relationship between excess demand and the inflation rate. 
therefore nests (to a reasonable approximation) a wide range of price-setting models. Constraining $\epsilon(\mathrm{L})$ to include only positive powers of $\mathrm{L}$ implies backward-looking wage-setting in the manner of Friedman and Phelps; setting $\epsilon(\mathrm{L})=\mathrm{L}^{-1}$ is consistent with Taylor's(1980) version of discrete time Calvo contracts; symmetry with respect to leads and lags is consistent with Fuhrer and Moore's (1995a) amendment of the Taylor-Calvo model. ${ }^{15}$

Demand and supply shocks $d_{t}$ and $s_{t}$ are white noise errors.

Since all alternative interpretations of (3) share the property that $\epsilon(1)=1$, all can be respecified, using the definition of expected variables, in the form

$\eta(L) \Delta \pi_{t} \quad=\quad \alpha y_{t}+z_{t}$

Where $\eta(L)(1-L) \equiv 1-\epsilon(L)^{16}, z_{t} \equiv \epsilon(L) \omega_{t}-\alpha s_{t}$ is a composite moving average error term, and $\omega_{\mathrm{t}+\mathrm{i}}$ $\left(\equiv \pi_{\mathrm{t}+\mathrm{i}}-\pi_{\mathrm{t}+\mathrm{i}}^{\mathrm{e}}\right)$ is an expectational error.

Equation (4) is the "accelerationist" representation of the long-run vertical Phillips Curve, which, it can be seen, is common to a wide range of wage- and price-setting models. Different models will have very different implications for short-run dynamic behaviour, and will imply very different approaches in empirically estimated form (since both left- and right-hand sides may in principle include forward-looking terms), but all share one common feature: inflation will be a unit root process given output.

Nonstationarity need not however result once system properties, including policy feedbacks through equation (1), are taken into account. The reduced form for inflation derived from equations (1), (2) and (4) is given by:

$\phi(L) \Delta \pi_{t}=\beta \pi_{t-1}+\psi_{t}$ away.

${ }^{15}$ Different specifications do imply different lag structures on output, but these have been simplified

${ }^{16}$ Since $\epsilon(\mathrm{L})$ can be expressed as:

$$
\begin{aligned}
\epsilon(\mathrm{L}) & =\quad \epsilon(1)-\epsilon^{\prime}(1)(1-\mathrm{L})+\epsilon^{\prime \prime}(1)(1-\mathrm{L})^{2}+\ldots . \\
& =1-\eta(\mathrm{L})(1-\mathrm{L})
\end{aligned}
$$


where $\phi(\mathrm{L})$ is a stationary lag polynomial, $\beta \equiv-\alpha(\lambda(\tau-1)+\mu \tau)$, and $\psi_{\mathrm{t}}$ is a stationary composite moving average error term. ${ }^{17}$ By comparison of equations (4) and (5), it is evident that the requirement for stability of the system is that output must, via monetary policy, be made a negative function of lagged inflation.

The implied condition for stationarity of the system, given $\alpha>0$, is given by:

$\tau>1-\frac{\mu}{\mu+\lambda}$

Note that a crucial feature of this condition is that it is solely determined by values of long-run multipliers, which are general across alternative specifications of the monetary policy rule and the inflation process. Expectations formation, whilst it may be very important for short-run dynamics, has no impact on stationarity properties. Note also that the responsiveness of the monetary policy rule to output is irrelevant.

Consider first the simplest case where $\mu=0$ (nominal interest rates have no separate impact on output). In this case stationarity of inflation (asuming stationarity of the implicit target rate) will depend solely on the magnitude of $\tau$ (the responsiveness of the "Taylor Rule" to the expected inflation rate). If this parameter exceeds one (ie if the real interest rate is a positive function of the expected inflation rate) the inflation rate will be stationary, despite the incipient nonstationarity arising from equation (4). ${ }^{18}$ Setting monetary policy in real terms (ie with $\tau=1$ ) will imply that the incipient unit root in the inflation rate arising from equation (3) goes through into system properties. Values of $\tau$ below unity (including the special case of $\tau=0$, implying constant nominal interest rates) will be destabilising.

${ }^{17} \phi(\mathrm{L})$ and $\psi_{\mathrm{t}}$ are defined by:

$$
\begin{array}{lll}
\phi(\mathrm{L}) & \equiv & \gamma(\mathrm{L}) \eta(\mathrm{L})+\alpha[\tau(\lambda+\mu) \zeta(\mathrm{L})+\beta] \\
\psi_{\mathrm{t}} & \equiv \quad[\alpha \beta(\mathrm{L})-\gamma(\mathrm{L}) \epsilon(\mathrm{L})] \omega_{\mathrm{t}}-\alpha\left[(\lambda+\mu)\left(\mathrm{u}_{\mathrm{t}}+\sigma(\mathrm{L}) v_{\mathrm{t}}\right)-\gamma(\mathrm{L}) \mathrm{s}_{\mathrm{t}}+\mathrm{d}_{\mathrm{t}}\right]
\end{array}
$$

where $\zeta(\mathrm{L})$ is defined by $\tau(\mathrm{L}) \equiv \tau[1-\zeta(\mathrm{L})(1-\mathrm{L})]$ (analogously to the definition of $\eta(\mathrm{L})$ ); $\gamma(\mathrm{L}) \equiv 1+\sigma(\mathrm{L})(\lambda+\mu) ; \beta(\mathrm{L}) \equiv \alpha[\lambda(\tau(\mathrm{L})-1)+\mu \tau(\mathrm{L})] ;$ and $v_{\mathrm{t}} \equiv y_{t}-y_{t}^{e}$.

${ }^{18}$ Taylor's(1993) imposed specification has this property, since it is explicitly set out in terms of the (backward-looking) real interest rate, with an implied value of $\tau=1.5$. This condition is also noted in the context of a stability condition in a continuous time model by Fuhrer \& Moore (1995c). 
In the more general case, however, where $\mu$ is non-zero (the nominal interest rate impacts separately on aggregate demand), the condition for stationarity becomes less stringent, depending on the relative magnitudes of $\mu$ and $\lambda$. As long as a rise in expected inflation is met by a sufficiently large rise in nominal rates, it will be possible to stabilise inflation even with a fall in real rates. Anticipating the empirical results of the next section, this property appears to be crucial in practice.

Assuming the conditions for stationarity hold, actual and target inflation (here normalised away) will be cointegrated, and hence the time series properties of both will be given by the properties of target inflation. Nonstationarity of the observed inflation rate could in principle reflect either nonstationarity of the system properties, as discussed above, or nonstationarity of the target inflation rate itself. ${ }^{19}$

\section{(ii) Implications for a Policy Loss Function}

Although the analysis has focussed on the issue of removing the unit root in inflation, it is clear that, more generally, the vigour with which the monetary authority responds to deviations of inflation from target (as captured here by the value of $\tau$ ) will have very important implications for the longhorizon predictability of inflation. and hence for welfare. Whilst a fully specified investigation of the welfare implications of this choice is beyond the scope of this paper, some feel for the implications can be arrived at with reference to an ad-hoc loss function, in conjunction with a simplified version of the model above. Suppose the policy loss function at time $t$ is given by:

$$
\Lambda_{t} \quad=\quad \sum_{i=0}^{H}(1+\theta)^{-i} E_{t}\left[(1-\chi) y_{t+i}^{2}+\chi \pi_{t+i}^{2}\right]
$$

where $\theta$ and $H$ are the policymaker's discount rate and horizon. Given the assumed normalisation of steady-state values to zero, $\Lambda_{\mathrm{t}}$ will simply be a weighted average of the variances of output and inflation at different forecast horizons, evaluated at time $t$.

Assume, further, for the sake of simplicity that $\mu=0$ (only real interest rates affect aggregate demand); $\tau(\mathrm{L})=\tau \mathrm{L} ; \tau>1$ (a simple backward-lookingTaylor Rule, ruling out explosive and unitroot solutions), $\sigma(\mathrm{L})=0$ (output does not directly enter into the rule), and $\eta(\mathrm{L})=1$ (the simplest

${ }^{19}$ Although if the target rate is itself endogenous to the current or lagged inflation rate this may imply a reduced form representation which is very close to that used here. Studies of "opportunistic" disinflation (eg Bomfim \& Rudebusch (1997)) typically have this property, albeit with the (somewhat arbitrary, and historically dubious) restriction that the target rate can only be affected by negative inflation shocks. 
possible backward-looking representation of inflation). Then inflation and output will be given by:

$$
\begin{aligned}
& \pi_{t} \quad=(1-\alpha \lambda(\tau-1)) \pi_{t-1}+\xi_{t} \\
& y_{t} \quad=\quad-\lambda(\tau-1) \pi_{t}+\zeta_{t}
\end{aligned}
$$

with both error terms white noise.

The two equations show that different values of $\tau$ will have very different implications for the longhorizon predictability of $\pi$ and $y$. As $\tau$ tends to one from above, inflation will become a unit root process, the variance of which rises linearly with the forecast horizon. The variance of $y$, in contrast, will tend to a finite value for all values of $\tau$, even at an infinite horizon, since as $\tau$ tends to unity, inflation drops out of the equation for output.

Given discounting, even if the policymaker has an infinite horizon, the loss function will still have a finite value for $\tau=1$, but it will increase highly nonlinearly as $\tau$ approaches one, for any non-zero value of $\chi$, the relative weight of inflation in the loss function. On the other hand, beyond a certain point, higher values of $\tau$ will also increase the value of the loss function, since any non-unit value will raise the variance of $y$ at all horizons, by increasing the volatility of real interest rates.

Figure 4 illustrates the typical shape of the implied tradeoff. ${ }^{20}$ It should be stressed that the precise form shown should not be taken as anything other than illustrative; the crucial feature is the extreme degree of nonlinearity as $\tau$ approaches the value which implies a unit root in in inflation. As equation (6) shows, if nominal interest rates impact on real activity, this value may be less than unity, but the extreme degree of nonlinearity around this value will remain.

The horizon of the policymaker will significantly affect the extent of the nonlinearity of the loss function around this point; but not elsewhere. This feature arises because of the interaction of a variance which, in the unit root case, rises linearly with the forecast horizon, with the discounting in the assumed structure of the loss function. Discounting will ultimately kill off the rising variance,

${ }^{20} \mathrm{Calculated}$ using the following parameter values: $\chi=0.5 ; \alpha=0.1 ; \lambda=2$. Policy innovations were set to zero, $d_{t}$ and $s_{t}$ were assumed to be orthogonal. The variance of $\pi$ one quarter ahead was normalised to unity. The assumed variance of $d_{t}$ was normalised relative to $\operatorname{var}\left(s_{t}\right)$ such that the variance of $y$ one quarter ahead was around 3 times that of $\pi$ (roughly consistent with average experience in a range of countries), when $\tau=1.5$. The three loss functions shown are normalised by scaling by $\sum_{i=0}^{H}(1+\theta)^{-i}$ such that an increase in the horizon does not increase the loss function, ceteris paribus. 
but does so only after a surprisingly long time (around 20 years, with the assumed discount rate of $5 \%)^{21}$

Perhaps the clearest implication of Figure 4 is that, given the extreme nonlinearity of the loss function when $\tau$ approaches unity, the precise value of $\tau$ which minimises the loss function is relatively unimportant, as long as the unit root is avoided. Given a reasonable degree of price stickiness in the short term, the payoff from raising $\tau$ beyond a certain point, in terms of reduced inflation uncertainty, falls off very rapidly, whereas the cost, in terms of higher induced variability of the real interest rate, and hence of output, rises steadily with $\tau$.

It is worth bearing in mind, however, that this approach ignores the issue of parameter uncertainty. This is probably a non-trivial issue given that the nonlinearity is specifically around the value of $\tau$ associated with a unit root in inflation. The empirical problems associated with clearly establishing the existence of a unit root are well-known, and were discussed briefly in Section II. The model suggests strongly that uncertainty as to whether there is a unit root in inflation is uncertainty about monetary policy. If parameter uncertainty were explicitly allowed for in the model (presumably by requiring the private sector to estimate $\tau$, rather than assuming it to be common knowledge), this would clearly tend to raise the optimal value of $\tau$.

\section{ESTIMATION RESULTS}

\section{(i) A Vector Autogressive Representation}

The mechanisms discussed in the previous section can be examined in an empirical representation of the model. The system can be given the following structural vector autoregressive representation:

$$
B \Delta X_{t}=c_{0+} C(L) \Delta X_{t-1}+\gamma X_{t-1}+e_{t}
$$

\footnotetext{
${ }^{21}$ If the one-step ahead variance of $\pi$ is normalised to unity, the discounted variance term for any horizon will equal $(1+\theta)^{-\mathrm{i}} \mathrm{i}$. This function reaches a maximum for $i \approx 1 / \theta$. It is beyond the scope of this paper to determine what might be viewed as the appropriate horizon for a loss function such as this. If the primary reason to dislike inflation uncertainty relates to financial contracts, then a horizon of 20 to 40 years appears sensible. An infinite horizon can only really be rationalised if future generations are viewed as suffering harm from inflation uncertainty. One can think of examples of this, such as institutions which are funded by perpetuities expressed in nominal terms; but these are fairly rarified.
} 
where $\mathbf{X}=\left(\begin{array}{lll}i & \pi & y\end{array}\right)^{\prime}, \mathbf{B}$ is a scalar matrix of contemporaneous response coefficients, $\mathbf{c}_{\mathbf{0}}$ is a vector of constant terms, $\mathbf{C}(\mathbf{L})$ is a matrix of lag polynomials capturing stationary transitional dynamics, $\gamma$ is a scalar matrix of long-run parameters, and $\mathbf{e}_{\mathrm{t}}$ is vector of orthogonal white noise disturbances. The three rows of equation (7) can be seen as empirical representations of equations (1), (2) and (4).

Note that, in estimation, both the estimated policy rule and inflation processes are given an explicitly backward-looking representation. But since the analysis of the previous section showed that expectations formation impacts solely on short-run dynamics, and not at all on stationarity properties, this is in fact a legitimate simplification. ${ }^{22}$

Perhaps of greater importance, in the estimated model as given by (7) the unobservable target rate of inflation (which in the analytical model was conveniently normalised to zero) must of necessity be proxied by a constant. Where the estimated system turns out to be stationary, this is a valid, indeed almost necessary restriction. ${ }^{23}$ Where the estimated system turns out to be non-stationary, however, there is clearly a risk that non-stationarity of the true target rate will be confounded with non-stationarity of the system. ${ }^{24}$

An additional complication is that the estimated system allows for an autoregressive component in $y$, which was simplified away in equation (2) of the analytical model. But it is straightforward to relate this more complex system to the conditions for stationarity of the simpler model of the previous section. The properties of the system depend on the rank of $\gamma$, the matrix of long-run parameters. If $\gamma$ is of full rank, then the system has a steady state solution for all three variables. ${ }^{25}$ Adapting the representation of the previous section to allow for more complex dynamics in $y$ would imply that $\gamma$ should have the following form:

\footnotetext{
${ }^{22}$ This simplification is indeed common to any empirical work where stationarity properties are inferred from implicitly backward-looking representations. Estimation allowing explicitly for forward-looking behaviour must in any case of necessity proxy expected values using current and lagged information: hence it is only the short-run dynamic responses which might be expected to differ.

${ }^{23}$ Strictly, the required restriction must be that the target inflation rate is itself stationary - but this in turn implies that the steady-state target inflation rate (or, equivalently, the long-horizon forecast of the target rate) must be a constant.

${ }^{24}$ Although in reduced form terms these may not be all that dissimilar - see Footnote 19.

${ }^{25}$ Since setting all difference terms to zero and solving for a steady state requires invertibility of $\gamma$. Note that a steady-state for $y$ implies that output is at its trend, or capacity level. Note also that the existence of a steady-state solution is a necessary, but not sufficent condition for stationarity - an issue discussed further in subsection (viii).
} 


$$
\gamma=\left[\begin{array}{ccc}
\gamma_{11} & \gamma_{12} & \gamma_{13} \\
0 & 0 & \gamma_{23} \\
\gamma_{31} & \gamma_{32} & \gamma_{33}
\end{array}\right]=\left[\begin{array}{ccc}
\gamma_{11} & 0 & 0 \\
0 & 1 & 0 \\
0 & 0 & \gamma_{33}
\end{array}\right]\left[\begin{array}{rrr}
1 & -\tau & -\sigma \\
0 & 0 & \alpha \\
-(\lambda+\mu) & \lambda & 1
\end{array}\right]
$$

Where $\gamma_{11}$ and $\gamma_{33}$ can be viewed as error correction coefficients, and hence are assumed negative. In this restricted version, $|\boldsymbol{\gamma}|$ can be expressed as:

$$
|\boldsymbol{\gamma}|=\gamma_{11} \gamma_{33} \beta
$$

where $\beta(\equiv-\alpha(\lambda(\tau-1)+\mu \tau))$ is defined as in equation (5). Hence the condition for a steady state solution of the estimated system is the the same as that for the stability of the analytical model (conditional on error correction coefficients being non-zero).

The empirical significance of the alternative mechanisms by which inflation can be rendered stationary can therefore straightforwardly be evaluated by tests on the elements of $\gamma$. In addition, a further convenient property of this representation is that it allows a direct test of the assumption that the "generalised Taylor Rule" representation of monetary policy is in fact a valid one, since all versions imply a non-zero value of $\gamma_{11}$, and hence a steady-state relationship between the nominal interest rate, the inflation rate and deviations of output from trend).

\section{(ii) Data, Time Series Properties and Sample Selection}

Estimation of the system given in (7) was carried out on quarterly data for three countries Germany, the United States, and the United Kingdom - which appear to be reasonably representative of the range of experience discussed in Section II. Detailed data definitions are given in the appendix.

The measure of short-term interest rates (i) was chosen, in each country, as that which appeared to reflect most strongly the implementation of monetary policy. Inflation $(\pi)$ was measured by consumer price inflation.

Deviations of output from trend/capacity $(y)$ were proxied by capacity utilisation . This measure is far from ideal, since it only covers manufacturing or industrial output, but, since (as discussed below) it appears to be "naturally stationary" it avoids the problems associated with arbitrary detrending 
procedures if a direct measure of output is used, or the unit root problems associated with use of, for example, the unemployment rate as an indicator of the cycle. There is also considerable evidence from at least one country (the UK - for a discussion see Salazar et al, 1997) that short-term movements in manufacturing output are strongly correlated with movements in the other output components.

The appendix also gives evidence on stationarity tests carried out on nominal interest rates and capacity utilisation. Since, as noted in Section II, the time series properties of inflation are ambiguous, it is unsurprising that this carries through, to a considerable extent, to the properties of nominal interest rates. Capacity utilisation appears clearly stationary - with very similar properties in all three countries.

The issue of sample selection in such exercises is a difficult one. A deliberate decision was taken to estimate the systems over a relatively long sample (from 1961 Q1 to 1994 Q4). In principle choosing a shorter sample might have avoided parameter instability arising from, for example, regime changes. But this argument should be treated with caution. On the one hand, the precise monetary regimes, pursued by the three central banks, changed or were affected by major shocks, on a number of occasions through this sample (obvious examples being the breakdown of the Bretton Woods agreement, the shortlived attempts at monetary base targeting in the US and the UK, the advent of the ERM, German unification, etc, etc). On the other hand the strictly institutional aspects of monetary policymaking were, in all three countries, barely changed at all through the entire sample. ${ }^{26}$

It could also be argued that the dangers of parameter instability due to monetary regime changes over the course of long samples are offset by the danger, if a shorter sample is chosen, of implicitly assuming that such changes are entirely exogenous to the underlying aims of policy. Thus, as examples, the attempts at monetary base control in the US and UK were, in both countries, associated with a move towards distinctly tighter policy in response to sharp rises in inflation in the late 1970s; in similar vein it might be argued that both the UK's entry to, and subsequent exit from, the ERM,

\footnotetext{
${ }^{26}$ Whilst some reference will be made below to stability of estimated systems over sub-samples, it should also be noted that estimating over split samples is subject to problems. It is common to look for a split around the start of the 1980s. Quite apart from the well-known dangers of spotting structural breaks with the benefit of hindsight, a glance at Figure 1 makes it evident that even in countries where inflation appears stationary (or at least nearly so) over the full sample, this is much less evident in a sample starting in the early 1980s, so that inference from this restricted sample appears risky. (A stationary representation of the shorter period would be highly dependent on initial observations which are clearly statistical outliers).
} 
whilst ostensibly exogenous regime changes, were in practice very closely related to the short-term aims of UK monetary policy. In contrast, whilst the Bundesbank also had to deal with at least as many regime changes of equivalent significance over this sample, this appears to have had remarkably limited impact on its behaviour. ${ }^{27}$ In addition, it is fairly obvious that long-run properties of the data, which are the primary consideration in this exercise, can only really be expected to emerge in long samples.

\section{iii) Identification}

Clearly a structural representation like (7) can only be derived by making identifying assumptions. The identification scheme used here is based on covariance restrictions: $\mathbf{B}$ is assumed to be upper triangular, with diagonal terms normalised to unity. The crucial assumption relates to the first row of B. Following an approach similar to Bernanke \& Blinder (1992), Christiano, Eichenbaum and Evans (1996), Bernanke \& Mihov (1997), Clarida et al(1997) and a number of other studies, interest rates are assumed to have no impact on either inflation or activity in the current period. This is also in line with the analytical approach used in Section III.

This identification scheme is, of course, untestable. But, following a similar line of reasoning to Bernanke \& Mihov (1996), the resulting estimate of $\mathbf{B}$ can at least be compared to the alternative extreme assumption with reference to priors on the signs of contemporaneous effects. The reduced form of (7) is given by:

$$
\Delta X_{t}=d_{0}+D(L) \Delta X_{t-1}+\delta X_{t-1}+u_{t}
$$

where, $\mathbf{d}_{\mathbf{0}}=\mathbf{B}^{-1} \mathbf{c}_{\mathbf{0}}, \mathbf{D}(\mathbf{L})=\mathbf{B}^{-1} \mathbf{C}(\mathbf{L}), \delta=\mathbf{B}^{-1} \gamma$, and $\mathbf{u}_{\mathrm{t}}=\mathbf{B}^{-1} \mathbf{e}_{\mathbf{t}}$ has a non-diagonal covariance matrix $\Upsilon$. In estimation, both the second and third elements of the top row of $\Upsilon$ are positive. This is in line with a contemporaneous “Taylor Rule". In contrast, if, eg output responded instantaneously (and, by assumption, negatively) to interest rates, but interest rates only responded to output with a lag, this would imply a negative covariance between the residuals of the two reduced form equations. The identification scheme used here, therefore, at least satisfies weak inequality conditions based on $a$ priori reasoning.

\footnotetext{
${ }^{27}$ Eichengreen(1995) argues along similar lines.
} 
In order to ensure that such a mechanism for setting interest rates would actually be feasible for central banks, given information available at the time, interest rates are measured at end-quarter, whilst inflation, and (for the US) capacity utilisation are measured at mid-quarter. Given the relatively timely nature of these figures, this is sufficient to ensure that they would have been available to policy makers. This is unfortunately not the case for capacity utilisation in the United Kingdom and Germany, which is only available as a quarterly average figure. However, given the timely availability of other indicators of cyclical movements in monthly terms ( $e g$ unemployment and industrial output) it does not appear too implausible to assume that central banks would, by the end of any given quarter, have been able to form a reasonable estimate of the rate of capacity utilisation in that quarter. Implicitly, though, in these two countries, the residual terms must include an element of measurement error. ${ }^{28}$

The ordering of $\pi$ and $c$ is less crucial: the residual covariance between the two reduced form equations is positive but small. Most sticky price models would imply the ordering used here, with some prices adjusting to shocks to output in the current period, but most reaction with a lag. The ordering of $\pi$ and $c$ is however irrelevant to the identification of the monetary policy reaction function, and is not crucial for the vertical Phillips Curve restriction, discussed in Section (v) below.

\section{(iv) Testing for system nonstationarity}

It is possible to test the system as a whole for nonstationarity, independently of the identification scheme. $^{29}$ Since such a test is the system equivalent of the ADF test for a single series, it is complicated by the fact that, under the null that $|\boldsymbol{\delta}|$ is zero, the distribution of standard test statistics will be non-standard. The rank deficiency testing procedure of Johansen (1991) usually applied to cointegration analysis can however be applied equally well in this context. Table 1 shows the results of Likelihood Ratio tests based on the eigenvalues of the long-run matrix. The crucial test statistic,

\footnotetext{
${ }^{28}$ Orphanides (1998) points out that the operational difficulties of implementing estimated monetary policy rules are often significant - he shows that the "Taylor Rule", as originally formulated in Taylor (1993) was dependent to a significant extent on data which were prone to major revision. Although this paper is far from being immune from this criticism, it should be noted that the major problems Orphanides identifies arose from the use of both price and pressure of demand indicators which came from the national accounts. An advantage of consumer price indices is that they are not subject to revision; and whilst capacity utilisation measures are revised in the US (but not in Germany or the UK), the extent of these revisions is less than those to detrended output, as used by Taylor - since this is subject both to revisions to GDP, and to the estimated trend.
}

${ }^{29}$ Since $|\boldsymbol{\delta}|=|\mathbf{B}||\gamma|$. If, as here, the diagonal elements of $\mathbf{B}$ are normalised to unity, the two determinants will be identical. 
shown in the third row, is of the null that $\delta$ is of rank two, against the alternative that it is of full rank. For both Germany and the United States, the null of system nonstationarity is rejected, if only marginally, at the $95 \%$ level. For the United Kingdom, however, the null cannot be rejected. ${ }^{30}$ These results, which appear to be complemented by model selection criteria, appear consistent with the univariate properties of inflation discussed in Section II. ${ }^{31}$

\section{(v) Testing for a vertical long-run Phillips Curve}

In principle, the apparent rejection of system nonstationarity in Germany and the USA might be attributable to the fact that the long-run Phillips Curve in these countries is not, in fact, vertical - in this case stationarity of inflation and nominal interest rates would in effect be attributable to a form of money illusion. The hypothesis that the long-run Phillips Curve is vertical can however easily be tested, and Table 2 shows that various versions of the restriction appear consistent with the data in all three countries. The first two rows condition on the identification scheme (hence on $\mathbf{B}$ ): the first (weaker) hypothesis is that the long-run parameters, $\gamma_{21}$ and $\gamma_{22}$ are equal and opposite; the second, that, consistent with the analytical model, they are both equal to zero. The last two rows show that this result is not conditional on the identification scheme: these tests were carried out on the long-

${ }^{30}$ Note that, interpreting the results for the United Kingdom in terms of the analytical model of Section III, this estimation procedure cannot distinguish between nonstationarity of the system, relative to a stationary target rate of inflation; and stationarity of the system, relative to a nonstationary target rate. For a sub-sample starting in 1984, the system appears stationary; but it is hard to know what inference to draw from this, in the light of the problems relating to sample selection discussed in subsection (ii).

${ }^{31}$ The picture is complicated somewhat by the long-run properties of real interest rates. In none of the countries is the evidence rejecting a unit root in the real rate unambiguous; but the degree of ambiguity appears to be linked to the uncertainty regarding the presence of a unit root in inflation.. If the real rate were clearly stationary, but inflation were nonstationary, one would expect to see a rejection of the null that $r \leq 1$ against the null that $r=2$, even when the null that $r \leq 2$ cannot be rejected against $r=3$, but this does not occur (the smallest eigenvalue is in all cases insignificantly smaller than the second-smallest). However, whilst it is hard conclusively to reject a unit root in the real rate, in no case is the range of long-run uncertainty, based on univariate properties, as great as for the inflation rate:

95\% Confidence Intervals for steady-state values, from stationary univariate time series representations

\begin{tabular}{|l|l|l|l|}
\hline & Germany & USA & UK \\
\hline Inflation & $1.8 \%-4.8 \%$ & $2.5 \%-7.1 \%$ & $2.7 \%-11.0 \%$ \\
\hline Real Short-Term Interest Rate & $1.5 \%-3.5 \%$ & $0.1 \%-4.4 \%$ & $-1.8 \%-5.0 \%$ \\
\hline
\end{tabular}

It is noteworthy that uncertainty regarding the steady-state real rate is least in Germany, where long-horizon inflation uncertainty is also lowest. Hence in the sample period, unit root uncertainty regarding inflation and real rates appear to go together; over long enough sample periods, one would however assume that they would be de-linked. 
run matrix in the reduced form ( $\delta$ ), which would be consistent with the ordering of $\pi$ and $y$ being reversed.

\section{(vi) Impulse Response Analysis}

To give some feeling for the nature of the estimated system, this section briefly examines the nature of its short-run dynamics. ${ }^{32}$ Given the identification scheme, the system can be viewed as a function of three orthogonal shocks: a monetary policy shock, a supply shock (which in a sticky price model becomes an inflation shock) and a real activity shock. Given orthogonality, it is valid to look at the impact on the system of a shock to each, taken individually. Figures 5 to 7 trace the impact of these shocks on the system. ${ }^{33}$

Figure 5 shows responses to a monetary policy shock, which are not dissimilar to those in other trivariate VARs. Note that, given the identification scheme (predicated implicitly on stickiness of inflation), a shock to nominal interest rates implies an identical shock to real interest rates. Since most past research has focussed on this aspect of the system, it is perhaps unsurprising that the issue of nominal vs real interest rate effects has not received all that much attention.

The panels for each country include an additional line to show the impact on the price level. This suggests the interpretation that a temporary shock to the interest rate in this framework can be viewed as a permanent shock to the target price level. It is noticeable that the impact of an initial $1 \%$ point shock to interest rates has very similar impacts on the price level in both the USA and Germany, and over a very similar time horizon. Note however that this is achieved with considerably smaller

${ }^{32}$ Two obvious caveats need to be made regarding this section of the paper. First, whilst expectational effects are irrelevant for long-horizon issues, they may in principle be very important for short-run dynamics the implicitly backward-looking representation used here should therefore be borne in mind. Second, the responses shown are of necessity averages of historic responses, and may be highly imperfect representations of current marginal responses.

${ }^{33}$ Note that the impact on both interest rates and inflation is shown in annual terms. The latter is derived by summing quarterly responses over four quarters, rather than by annualisation. 
effects on output in the United States, reflecting the slower response of prices to output in Germany (a feature also evident in Figure 6). ${ }^{34}$

The bottom panel shows that the estimated responses to a monetary policy shock in the UK contain a feature which has been noted in the past as a feature of empirical macro-models ( $\mathrm{eg}$ Bank of England,1990): namely the very marked perverse short-term response of prices to a rise in interest rates. It should be stressed that this feature does not reflect any direct effect of interest rates on the price level via mortgage interest payments (which are included in the headline Retail Price Index), since the measure of consumer prices used here excludes this component. The responses therefore suggest a perverse impact on underlying price inflation. This presumably reflects the role of the headline RPI (and hence interest rates) in wage bargaining (for discussion of which, see Bank of England (op cit)). In the other two countries there is also a very slight positive response within the first one or two quarters (which only shows up for longer in the charts due to the use of the year-onyear, rather than quarterly inflation rate), but this phase passes very rapidly.

The responses to an inflation shock, shown in Figure 6, appear to confirm prior expectations: both the Bundesbank and the Federal Reserve respond actively to an inflation shock; but the Bank of England's response is, in contrast, minimal. It is noteworthy that the Bundesbank's response is the most rapid and aggressive of the three. As a result, the process of stabilisation after the shock is markedly more rapid: the impact of the shock on both German inflation and interest rates has essentially disappeared within five years, and on activity within six or seven, whereas the impact on inflation in the US takes around eight years to unwind, and the impact on activity yet longer.

Responses in the United Kingdom are even more prolonged. It should be borne in mind, of course, that, given the fact that the reduced rank restriction on $\gamma$ cannot be rejected for the UK case, the implication, in terms of the impulse responses, is that it is impossible to reject the hypothesis that UK inflation shocks persist indefinitely.

\footnotetext{
${ }^{34}$ This exercise is not the same as that usually carried out to calculate the "Sacrifice Ratio", which is the output cost of an assumed permanent fall in the target inflation rate. Arguably the approach here is more data-consistent, since if, empirically, the inflation rate is stationary, this must imply that any changes in the target inflation rate have been temporary, as examined here. Conversely, had sustained changes in the target inflation rate occurred, this would result in observed inflation being non-stationary. There is a degree of schizophrenia in much empirical literature in this area, which simultaneously assumes stationarity of inflation, and the existence of sustained shocks tothe target inflation rate.
} 
A crucial feature of the responses of all three central banks, which is discussed further in the next section, is that, though nominal interest rates rise after an inflation shock, in all three countries, the real rate falls. The vigour of the Bundesbank's response in setting nominal rates only serves to reduce the extent of the fall in real rates, it is not sufficient to change its sign. Only in the case of the US does the real rate rise after an inflation shock, but even here, after a delay of nearly five years and by this stage this response only serves to prolong the real effects of the initial shock. By implication, therefore, the responses of the real economy to the monetary tightening which the inflation shock stimulates are due to changes in the nominal, and not the real interest rate.

The relative vigour of the responses of monetary policy to real shocks, shown in Figure 7, is distinctly different. In this case, the Federal Reserve emerges as much more active than the Bundesbank. This is in line with expectations, given the Federal Reserve's remit to take account of the state of the real economy in its operations, in contrast to the Bundesbank, which only has a formal responsibility for price stability.

(vii) The Relative Importance of Monetary Policy vs Nominal Interest Rate Effects on Activity

Are the differences between the three estimated systems driven mainly by differences in monetary policy, or by the behaviour of the real economy? This issue can be examined by statistical tests on the critical parameters which may ensure that the system is stationary. The stability condition in equation (6), which also determines whether $|\gamma|$ differs from zero in equation (8) is driven by two critical mechanisms: if the economy is entirely "real", then monetary policy needs to ensure that the real rate of interest responds positively to the inflation rate (ie monetary policy is not set solely in real terms); this requirement becomes less stringent if aggregate demand is affected by the nominal rate of interest. Table 3 shows tests of the statistical significance of these two alternative mechanisms. ${ }^{35}$ This brings out a very clear result. For two of the three countries, the United Kingdom and Germany it is impossible to reject the hypothesis of "Real Monetary Policy", ie, that the real interest rate only responds to real activity (equivalent to $\tau=1$ in the analytical model). The Bundesbank, despite its aggressive anti-inflationary stance, has nonetheless followed a version of the "Taylor Rule" which, if applied to an economy which only responded to real magnitudes, would not render the inflation

\footnotetext{
${ }^{35}$ Both tests are carried out on the version of the structural model with the restriction of a vertical Phillips Curve imposed, but results for the unrestricted model are virtually identical (details can be obtained from the author).
} 
rate stationary. ${ }^{36}$ But in all three countries, the restriction that only real interest rates affect aggregate demand is strongly rejected. Hence monetary policy can in principle stabilise the system even with values of $\tau$ less than unity.

These test statistics do not however tell the full story. Tables 4-6 give further details of the estimated parameters for all three countries, together with associated p-values for the hypothesis that a given parameter is zero. Table 4 shows the elements of $\gamma$, the long-run matrix in (7); Table 5 gives implied "Taylor Rule" parameters; and Table 6 gives the elements of $\mathbf{B}$, the matrix of contemporaneous responses. Examination of these parameters brings out a number of important features:

- For all three countries, $\gamma_{12}$, the response of the change in interest rates to lagged inflation, is, crucially, statistically different from zero. There are however important differences between the three countries in the impact of this parameter.

- In terms of the assumed underlying interest reaction function, or "Taylor Rule", it is not the magnitude of $\gamma_{12}$, but of $\tau\left(\equiv-\gamma_{12} / \gamma_{11}\right)$, which is crucial for stability. Even when nominal interest rates have effects on real activity, the magnitude of $\tau$ is still crucial for the stability of the system.

- As compared to the Bank of England, the Bundesbank's greater success in stabilising inflation can be attributable to a combination of a higher implied value of $\tau$ (shown in Table 5) and a more rapid rate of adjustment of interest rates to inflation. This latter property, evident in the impulse responses, is in turn largely attributable to a combination of a larger "error correction" coefficent $\left(\gamma_{11}\right.$, shown in Table 4$)$ and a higher instantaneous response $\left(b_{12}\right)$ shown in Table 6.

- This comparison cannot however meaningfully be carried out in relation to the USA, since for this country, the top left-hand element, $\gamma_{11}$, is insignificantly different from zero. The implications of this parameter value, which effectively invalidates the "Taylor Rule" representation over the sample period in question, are discussed in the next subsection.

${ }^{36}$ Clarida \& Gertler (1997) also find a similar result, but show that, if asymmetry of policy responses to positive and negative deviations of inflation from target is allowed for, the implied coefficient on positive deviations is significantly greater than unity. 


\section{(viii) The "Taylor Rule" as a Representation of US Monetary Policy}

As noted in the previous subsection, rather surprisingly (given that the original specification was derived as a representation of Federal Reserve policy under Alan Greenspan), the "Generalised Taylor Rule" representation does not appear to be robust for the US over longer periods. Whilst Table 4 shows that all three elements in the top row of $\gamma$ are statistically signficant for both Germany and the United Kingdom, implying that the "Taylor Rule" is a valid representation, the first element for the United States is insignificantly different from zero, implying that it is not. A zero value of $\gamma_{11}$, combined with non-zero values of $\gamma_{12}$ and/or $\gamma_{13}$, implies that the change in the nominal interest rate is a function of the levels of inflation and/or deviations of output from capacity. ${ }^{37}$

Policy does not necessarily require to be represented as a "Taylor Rule" in order to have stabilising properties. However, the characteristics of the observed US reaction function may possibly go some way towards an explanation of the relative lack of success of the Federal Reserve in stabilising inflation, historically, at least as compared to the Bundesbank.

Even when $\gamma_{11}$ is zero, it should be stressed, $|\gamma|$ does not necessarily go to zero, ${ }^{38}$ and the results in Table 2 implies that it it is indeed significantly different from zero in the US case. But it should also be borne in mind that invertibility of $\gamma$ is a necessary, but not sufficient condition for system stability - it ensures the existence of a steady-state solution; it does not ensure that the system converges to this steady state. Put more technically, invertibility of $\gamma$ implies that none of the eigenvalues of $\gamma$ is zero; it does not imply that they are all negative.

It can be shown (see Wright, 1997) that the parameter values implied by the "Taylor Rule" result in both necessary and sufficient conditions for system stability being met. This result is however not so clear-cut for reaction functions of the type which the results above suggest appear to have been more applicable to the US. Furthermore, it turns out that this caveat is empirically important. Numerical estimates of the eigenvalues of $\gamma$ for the United States show that two out of the three have positive (albeit statistically insignificant) real parts. However, necessary and sufficient conditions for stability relate to the eigenvalues, not of $\gamma$, but of $\mathbf{B}^{-1} \gamma$ - all three of these have negative real parts.

\footnotetext{
${ }^{37}$ Wright (1997) shows that, given certain parameter restrictions on $\gamma$, such a specification can be derived from the textbook LM Curve.

${ }^{38}$ This is not immediately evident from the definition of $|\gamma|$ given in equation (8), which appears to suggest the contrary. However, it is the factoring of $\gamma$ which causes the apparent confusion. When $\gamma_{11}$ is zero, $\gamma$ is still invertible, but the factoring is impossible.
} 
Rather surprisingly, that is, contemporaneous responses may, for such reaction functions, be crucial for long-term stability, whereas when policy follows a Taylor Rule they are not.

Whilst this feature of the data casts doubt on the "Taylor Rule" representation as a historic descriptive of US monetary policy over the past thirty years or so, it does not necessarily invalidate it as a description of Federal Reserve policy in more recent years. Much more crucially, this discussion if anything reinforces the relevance of the Taylor Rule as a prescriptive tool (the purpose for which it was originally primarily intended), since it is more robust as a stabilising mechanism than the average reaction function that appears to have been employed in practice in the United States. $^{39}$

\section{NOMINAL INTEREST RATES, REAL ACTIVITY AND LONG-HORIZON UNCERTAINTY}

As noted previously, there is considerable empirical evidence from a range of studies, including this paper, that nominal short-term interest rates have significant effects on real activity. ${ }^{40}$ Both the analytical model of Section II and the empirical results of Section III suggest that these effects may have important implication for the form of the "Taylor Rule". In an economy in which nominal rates have important real effects, the specification originally proposed in Taylor (1993), in which real short-term rates respond positively to deviations of inflation from target may in practice be excessively stringent. Whilst it would certainly achieve the aim of reducing long-horizon uncertainty, by rendering the inflation rate stationary, a less tough policy, which raised nominal rates by less than inflation, might also achieve the same aim, at a lesser output cost.

${ }^{39}$ The potentially destabilising properties of reaction functions of this general form were first pointed out by Fuhrer and Moore (1995c) For more detailed discussion of this issue, and of the robustness of alternative monetary policy reaction functions see Wright, (1997).

${ }^{40}$ It should be noted in this context that it is very difficult to distinguish empirically between the separate impacts of nominal interest rates, real interest rates and inflation rates, since, using a backward-looking approach, one can always be derived by identity from the other two. Thus any test for the significance of nominal interest rates, for a given impact of real rates, has an identical p-value to a test for the significance of the impact of the inflation rate, for a given impact of real rates. However, for all three countries, since real interest rates have at most marginally statistically significant effects on output (very similar results are also found for other countries), a rationale for nominal interest rate effects on activity which asserted that these were really (negative) inflation rate effects would have very strong implications. Monetary policy in such a world would either be entirely powerless to affect output, or would work exclusively through real balance effects. Independent empirical support for this latter mechanism is, however, weak to say the least, even in countries like Germany which have at least paid lip service to monetary targets (see Bernanke \& Mihov, 1997). 
But this conclusion generates something of a paradox, since real activity can only respond to nominal interest rates in an economy where monetary policy does achieve stationarity of inflation. This can be understood with respect either to statistical, or economic arguments.

The statistical argument is straightforward. The deviation of output from trend, (or the empirical representation used here, capacity utilisation) must, by construction, be a stationary series. There can be no long-run relationship between a stationary series and a nonstationary series - thus there can only be a long-run relationship between output deviations and the nominal interest rate if the latter, and hence inflation, are stationary. ${ }^{41}$

An economic argument draws on the rationale for the impact of nominal interest rates proposed by Fuhrer and Moore (1995b). They assume that activity is driven by an unobservable forward-looking real long-term rate, the time series properties of which resemble the short-term nominal rate. But this will only be the case if monetary policy achieves the aim of rendering inflation stationary (in which case expected deviations in long-run inflation will be small).

This suggests a possible additional payoff to any systematic monetary policy which reduces longhorizon inflation uncertainty - it may also result in an increased power of monetary policy, acting through the nominal, as opposed to real interest rate. Certainly, systematic monetary policy which does not reduce long-horizon inflation uncertainty must of necessity rely all the more on real interest rate effects, the greater this inflation uncertainty becomes.

This would imply the empirical prediction that in countries with low levels of long-horizon inflation uncertainty there should be a stronger tendency for nominal interest rates to impact on real activity than in countries where inflation is more unpredictable over long horizons.

Figure 8 provides some simple visual evidence in favour of this hypothesis. It shows a scatter diagram based on data for 13 OECD economies. The strength of nominal interest rate effects on nominal activity (proxied by p-values from three different tests of the null of Granger-non-causality from nominal rates to capacity utilisation) is plotted against long-horizon inflation uncertainty (proxied by the confidence interval of steady-state inflation (as defined in Section II)). A low p-value implies that the null of non-causality is rejected - the figure makes clear that, for all three testing

\footnotetext{
${ }^{41}$ Assuming that real interest rates are stationary - see Footnote 31.
} 
procedures, the null is rejected markedly more often in countries with low levels of inflation uncertainty. ${ }^{42}$

\section{CONCLUSIONS}

The main theme of this paper has been the nature of the link between systematic monetary policy and long-horizon inflation uncertainty, in a world of sticky prices. It is unsurprising that the more vigorously monetary policy responds to deviations of inflation from target, the more predictable inflation will be in the long run. But the nature of the payoff from more vigorous monetary policy is highly nonlinear - the crucial objective of monetary policy is therefore likely to be that of removing the incipient unit root in inflation which arises out of the Vertical Phillips Curve. Once this objective is achieved, the gains from further "long-run stabilisation" of inflation are likely to be much more modest - given that any such gains must be made at the expense of increased volatility of interest rates, and therefore activity.

At the start of the paper reference was made to the shift from a loss function defined on the means of inflation and output, to a function one moment higher. The focus on long-horizon inflation uncertainty suggests a link between the two, which might appear at first sight to be somewhat paradoxical. Suppose the monetary policymaker is not interested in mean inflation at all, but simply in its uncertainty; and that, due to sticky prices, the primary impact of monetary policy is on longhorizon uncertainty. The analysis of this paper suggests that it would be in the interests of such a policymaker to behave as if the mean inflation rate mattered a great deal - ie, to pick some fixed target rate, and stick to it through thick and thin, since the single most crucial element in reducing inflation uncertainty in the long run is to remove the incipient unit root.

A further, more tentative, conclusion to be drawn out of the paper is that the nature of systematic monetary policy may itself affect the transmission mechanism by which it affects the economy. If inflation is made more predictable, a given change in nominal interest rates is likely to have a greater effect on the real economy. This may in turn affect the nature of the systematic policy rule, through the required degree of vigour with which interest rates need to respond to inflation.

\footnotetext{
${ }^{42} \mathrm{~A}$ similar degree of association is also evident if long-horizon inflation uncertainty is replaced with long-horizon interest rate uncertainty. Details of estimation procedures and data are given in the appendix.
} 
This paper also has some implications which go beyond the analysis of the monetary policy process and inflation. Since long-horizon uncertainty in inflation is passed through to a great extent into a similar degree of long-horizon uncertainty in nominal interest rates, there are clearly important implications for the way financial markets price assets which are a function of expectations of nominal interest rates over long horizons. Whilst the finance literature has to some extent addressed the implications of abandoning the assumption that nominal interest rates are stationary, it has done so, essentially, in a vacuum. But this paper has shown that this issue cannot properly be examined without taking monetary policy into account. ${ }^{43}$

\section{Appendix}

\section{(i) Data Definitions}

The measure of nominal interest rates $(i)$ was chosen as that which best captured the direct effect of monetary policy: for Germany the Call Money Rate (following Clarida \& Gertler (1997); for the US the Fed Funds Rate (following Bernanke \& Blinder(1992), Taylor(1993) and many other studies; for the UK the interbank rate.

CPI inflation $(\pi)$ was measured in quarterly terms in order to avoid the moving average process induced by using year-on-year rates. Quarterly dummies were included in all estimated equations to capture seasonal effects in price indices. For the UK, the retail price index excluding mortgage interest payments was used in order to avoid any direct dependence of the the inflation rate on the interest rate.

For the UK, a prior transformation was applied to the only available capacity utilisation indicator, which is the proportion of firms operation at full capacity, as reported to the Confederation of British Industry Quarterly Survey. Minford \& Wren-Lewis (1988) show that, if the utilisation rate of individual firms follows a logistic distribution, then true aggregate capacity utilisation $(c)$ will be related to the indicator $(f)$ as follows:

$\log \mathrm{c}=\rho \log (\mathrm{f} /(1-\mathrm{f}))$

The parameter linking the two, $\rho$, is unobservable, but its value will not affect estimation properties, except in terms of the magnitude (but crucially, not statistical significance) of parameter estimates. In order to allow comparability between the impulse response properties of output, however, the value of $\rho$ was chosen which implies that innovations to capacity are orthogonal to innovations to capacity utilisation. Reassuringly, this value results in time series properties of the implied UK capacity utilisation series which are very similar to those of the series for Germany and the United States.

${ }^{43}$ There are two areas in finance where the analysis of this paper has obvious implications. The debate initiated by Shiller (1979) on the "excess volatility" of long-term interest rates, is crucially affected by whether or not nominal interest rates are stationary. Wright (1995) suggests that some of the associated market inefficiencies may be attributable to markets taking insufficient account of the stabilising effect of monetary policy. Another area where this issue is likely to be important is the vast literature on the "equity premium puzzle". The general assumption in this literature is that the long-term nominal bond yield offers a "safe" return; but the analysis of this paper shows that the extent to which this return is safe in real terms will depend crucially on the degree of inflation uncertainty over the term of the bond, and hence on the stabilising properties of monetary policy. 
The unit root tests carried out for the thirteen countries shown in Figure 2 were standard ADF tests, including four lags of the dependent variable.

The table below gives the results of unit root tests on nominal interest rates $(i)$ and capacity utilisation $(y)$, over the sample period used in estimating equation (7).

Table A1. Augmented Dickey Fuller Statistics for the sample 1961 Q2-1994 Q4

\begin{tabular}{|l|l|l|l|l|l|}
\hline \multicolumn{3}{|c|}{ Germany } & \multicolumn{2}{l|}{ United States } & \multicolumn{2}{l|}{ United Kingdom } \\
\hline$i$ & $y$ & $i$ & $y$ & $i$ & $y$ \\
\hline-3.66 & -3.96 & -2.30 & -3.53 & -2.45 & -3.62 \\
\hline
\end{tabular}

Note that the ADF test appears to be closer to rejecting a unit root in $i$ than in $\pi$. This finding is in itself consistent with the analysis of the paper. If $\pi$ is nonstationary, or nearly so, due to insufficient responsiveness of $i$ to deviations of $\pi$ from target (ie a low value of $\tau$ ), then it would be expected that observed $i$ would be more stable than observed $\pi$. In the extreme, indeed, as noted in Section II an economy with perfectly stable $i$ would have perfectly unstable $\pi$.

\section{(iii) Derivation of Figure 8}

The calculations underlying Figure 8 were carried out as follows. For each country, the indicator of activity was again capacity utilisation, or an indicator thereof, from the OECD's Main Economic Indicator database. The availability of such indicators over a sufficiently long sample (the minimum used was a sample starting in 1980, whilst for most countries data were available from at least the early 1970s) was the sole consideration involved in selection of the countries used. The full list of countries chosen was: Germany, Switzerland, Denmark, The Netherlands, The United States, Japan, Canada, New Zealand, Australia, Great Britain, Spain, France, Italy. Whilst ideally (for consistency with the approach in the rest of the paper) the nominal interest rate used should be a market short-term interest rate closely associated with monetary policy, these were not sufficiently widely available, over sufficiently long samples, for this to be feasible; instead, in default of such series, a long-term bond yield (either from the same database, or from the IMF database) was used throughout.

Standard Granger Causality tests were then carried out for each country. In the simplest version, the log of capacity utilisation (or the indicator thereof, transformed as in equation (10)) was regressed on four lags of itself, plus four lags of the nominal interest rate. The alternative specifications also included either four lags of the inflation rate, or four lags of the ex-post real interest rate. In all three cases, the figure shown on the yaxis of Figure 8, is the p-value for an F-Test for the joint signficance of of all four lags of the nominal interest rate in this regression (ie, a test of the null of non-causality).

Confidence intervals for steady-state inflation on the $x$-axis are derived consistently with those discussed in Section II. For all countries, the price index used was the consumer price index, again from the OECD database. The sample used started earlier (1961 Q2) than the sample used for causality tests, given the implicit assumption that the past properties of inflation will affect the mechanism by which nominal rates impact on the real economy; but in practice the sample chosen has minimal effects on the results. 


\section{References}

Alogoskoufis, G, and Smith, R (1991), "The Phillips Curve, the Persistence of Inflation, and the Lucas Critique: Evidence from Exchange Rate Regimes", American Economic Review, Vol 81, no 5, pp 1254-1275

Bank of England (1990), "The interest rate transmission mechanism in the United Kingdom and overseas", Quarterly Bulletin May 1990, pp 198-214

Ball, L (1997) “Efficient Rules for Monetary Policy”, NBER Working Paper 5952, March 1997

Ball, L and Cecchetti S G (1990), "Inflation and Uncertainty at Short and Long Horizons", Brookings Papers on Economic Activity, pp 215-54

Batini, N, Haldane, A (1998), "Forward-Looking Rules for Monetary Policy” NBER Working Paper no 6543

Bernanke, B S \& Blinder, A S (1992), "The Federal Funds Rate and the Channels of Monetary Transmission", American Economic Review 82 (4) pp 901-921

Bernanke, B S \& Gertler, M (1995), "Inside The Black Box: The Credit Channel of Monetary Policy Transmission," Journal of EconomicPerspectives; 9(4), Fall 1995, pages 27-48.

Bernanke, B S \& Mihov, I (1996), "The Liquidity Effect and Long-run Neutrality: Identification by Inequality Constraints", unpublished, Princeton University and INSEAD.

Bernanke, B and Mihov, I (1997) "What does the Bundesbank target?" European Economic Review 41 pp $1025-1053$

Blinder, A S \& Deaton A (1985), "The time-series consumption function revisited", Brookings Papers on Economic Activity pp 183-241

Bomfim, A \& Rudebusch G (1997), "Opportunistic and Deliberate Disinflation Under Imperfect Credibility", unpublished, Federal Reserve Board and Federal Reserve Bank of San Francisco

Christiano, L, Eichenbaum, M, \& Evans, C (1996) "The Effects of Monetary Policy Shocks: Evidence from the Flow of Funds", Review of Economics and Statistics; 78(1), February 1996, pages 16-34.

Clarida R \& Gertler M (1997) "How the Bundesbank Conducts Monetary Policy",-in C Romer and D Romer (eds) Reducing Inflation Chicago, University of Chigago Press 1997

Clarida, R., Gali, J, \& Gertler, M (1998) "Monetary policy rules in practice: Some international evidence" European Economic Review 42 (6), June 1998, pp 1033-1067

Dickey, D A \& Fuller,W A (1979) "Distribution of the estimators for autoregressive time series with a unit root", Journal of the American Statistical Association 74, pp 427-431

De Jong, D N, Nankervis, J C, Savin, N E and Whiteman, C H (1989), "Integration vs trend stationarity in macroeconomic time series", University of Iowa, Working Paper no 89-99

Eichengreen, B (1995) "The Endogeneity of Exchange Rate Regimes", in P B Kenen (ed) Understanding Interdependence - the Macroeconomics of the Open Economy, Princeton University Press.

Evans, M \& Wachtel, P (1993), "Inflation Regimes and the Sources of Inflation Uncertainty", Journal of Money, Credit and Banking, Vol 25, no. 3, pp 475-511

Fair, R (1979) "An Analysis of a Macroeconometric Model with Rational Expectations in the Bond and Stock Markets”, American Economic Review, September 1979, 539-552. 
Fuhrer, J C \& Moore G R (1995a) “Inflation Persistence”, Quarterly Journal of Economics 110(1) pp 127-59

Fuhrer, J C \& Moore G R (1995b) "Monetary Policy Tradeoffs and the Correlation between Nominal Interest Rates and Real Output", American Economic Review 85 (1) pp 219-39

Fuhrer, J C \& Moore G R (1995c) "Forward-Looking Behavior and the Stability of a Conventional Monetary Policy Rule"Journal of Money, Credit,and Banking; 27(4), Part 1 Nov. 1995, pages 1060-70.

Grubb D B \& Symons J S V (1985), "Bias in Regressions with a Lagged Dependent Variable", University College London Discussion Paper: 85-28

Johansen, S (1991), "Estimation and Hypothesis Testing of Cointegrating Vectors in Gaussian Vector Autoregressive Models", Econometrica 59, pp 1551-80

Klein, B (1975), "Our New Monetary Standard: The Measurement and Effects of Price Uncertainty, 18801973", Economic Inquiry, Vol 13, December 1975, pp 461-484

Minford, M and Wren-Lewis, S (1988), "Manufacturing Capacity: A Measure Derived from Survey Data using the Kalman Filter", National Institute of Economic and Social Research Discussion Paper no 146

Orphanides, A (1998) "Monetary Policy Based on Real-Time Data", Federal Reserve Board, Finance and Economics Discussion Series 1998-03

Pesaran, M H, Shin Y \& Smith R J (1997), "Structural Analysis of Vector Error Correction Models with Exogenous I(1) Variables", University of Cambridge, Department of Applied Economics, Working Paper no 9706

Roberts, J M (1997) “Is Inflation Sticky?” Journal of Monetary Economics, 39(2), pp 173-96.

Salazar, E, Smith, R, Weale, M \& Wright, S H (1997) “A Monthly Indicator of GDP” National Institute Economic Review No. 161, July 1997, pp 84-90

Shiller, R J (1979) "The volatility of long-term interest rates and expectations models of the term structure", Journal of Political Economy Vol. 87, No 6, pp 1190-1219

Taylor, J B (1980) “Aggregate Dynamics and Staggered Contracts”, Journal of Political Economy, 88(1), pages 1-23.

Taylor, J B (1993) “Discretion vs Policy Rules in Practice", Carnegie Rochester Series on Public Policy 39(0) pp 195-214

Taylor, J B (1994) “The Inflation-Output Variability Tradeoff Revisited”, in Fuhrer, J (ed) Goals, Guidelines and Constraints Facing Monetary Policymakers, Federal Reserve Bank of Boston Conference Series No. 38

Wright, S H (1995) "How to make money in the bond market: international evidence of inefficiency, and what it suggests about the way markets view monetary policy", The Manchester School, Volume LXII, June 1995, pp 22-39

Wright, S H (1997), "Explosive Features of Two Textbook Macro Models", Unpublished, University of Cambridge. 
Table 1. Testing for System Non-Stationarity

( $r$ refers to rank of long-run matrix)

\begin{tabular}{|c|c|c|c|c|c|}
\hline \multicolumn{3}{|c|}{ Johansen's LR Test on Maximal Eigenvalue } & \multirow[t]{2}{*}{ Germany } & \multirow[t]{2}{*}{ USA } & \multirow[t]{2}{*}{ UK } \\
\hline Null & Alternative & $95 \%$ Critical Values $^{44}$ & & & \\
\hline$r=0$ & $r=1$ & 22.04 & $30.05^{* *}$ & $64.2 * *$ & $37.2 * *$ \\
\hline$r \leq 1$ & $r=2$ & 15.87 & $14.46^{*}$ & 10.54 & 8.8 \\
\hline$r \leq 2$ & $r=3$ & 9.16 & $10.73 * *$ & $9.28 * *$ & 5.8 \\
\hline \multicolumn{6}{|c|}{ Implied Value of $r$ using Model Selection Criteria } \\
\hline \multicolumn{3}{|c|}{ Akaike Information Criterion } & 3 & 3 & 3 \\
\hline \multicolumn{3}{|c|}{ Schwarz Bayesian Criterion } & 3 & 1 & 1 \\
\hline \multicolumn{3}{|c|}{ Hannan-Quinn Criterion } & 3 & 3 & 1 \\
\hline
\end{tabular}

(** significant at $95 \%$ level; ** significant at $90 \%$ level)

Table 2. Wald Tests of Vertical Phillips Curve Restrictions (P-values $\left.{ }^{45}\right)$

\begin{tabular}{|l|l|l|l|}
\hline Restriction & Germany & USA & UK \\
\hline $\mathrm{h}_{0}: \gamma_{21}=\gamma_{22}$ & 0.58 & 0.94 & 0.99 \\
\hline $\mathrm{h}_{0}: \gamma_{21}=\gamma_{22}=0$ & 0.47 & 0.88 & 0.89 \\
\hline $\mathrm{h}_{0}: \alpha_{21}=\alpha_{22}$ & 0.45 & 0.82 & 0.98 \\
\hline $\mathrm{h}_{0}: \alpha_{21}=\alpha_{22}=0$ & 0.49 & 0.91 & 0.87 \\
\hline
\end{tabular}

${ }^{44}$ Critical values are from Pesaran et al (1997) and are based on the assumption that there are no deterministic trends in the three series, implying restrictions on intercepts which ensure that these go to zero under the null. Note that this restriction raises critical values significantly relative to test statistics, hence makes rejection of the null more marginal. Details of test statistics with unrestricted intercepts are available from the author.

${ }^{45}$ Note that these $\mathrm{p}$-values assume stationarity. The results in Table 1 suggest that this is appropriate in the case of Germany and the United States, but imply that those for the United Kingdom should be treated with caution, as should those in later tables. 
Table 3. Tests of alternative stabilising mechanisms (P-Values).

\begin{tabular}{|l|l|l|l|}
\hline & Germany & USA & UK \\
\hline $\begin{array}{l}\text { t-test of "real monetary policy" } \\
\left(\mathrm{h}_{0}: \gamma_{11}=-\gamma_{12} \rightarrow \tau=1\right):\end{array}$ & $\begin{array}{l}0.07 \\
(.948)\end{array}$ & $\begin{array}{l}-3.79 \\
(.000)\end{array}$ & $\begin{array}{l}-0.49 \\
(.625)\end{array}$ \\
\hline $\begin{array}{l}\mathrm{t} \text {-test of no nominal interest rate effects on activity } \\
\left(\mathrm{h}_{0}: \gamma_{31}=-\gamma_{32} \rightarrow \mu=0\right)\end{array}$ & $\begin{array}{l}-3.79 \\
(.000)\end{array}$ & $\begin{array}{l}5.70 \\
(.000)\end{array}$ & $\begin{array}{l}-3.48 \\
(.001)\end{array}$ \\
\hline
\end{tabular}

Table 4. Restricted Estimates of $\gamma$ (P-values in parentheses):

\section{Germany}

\begin{tabular}{|l|l|l|l|l|}
\hline response of & to: & $i_{t-1}$ & $\pi_{t-1}$ & $y_{t-1}$ \\
\hline$\Delta i$ & -0.134 & $\begin{array}{l}0.138 \\
(.021)\end{array}$ & $\begin{array}{l}0.0076 \\
(.132)\end{array}$ \\
\hline$\Delta \pi$ & 0 & 0 & $\begin{array}{l}.031 \\
(.005)\end{array}$ \\
\hline$\Delta y$ & 0 & $-001)$ \\
\hline & -0.795 & $\begin{array}{l}-0.723 \\
(.115)\end{array}$ & $\begin{array}{l}-0.171 \\
(.000)\end{array}$ \\
\hline
\end{tabular}

\section{United States}

\begin{tabular}{|c|c|c|c|c|}
\hline response of & to: & $i_{t-1}$ & $\pi_{t-1}$ & $y_{t-1}$ \\
\hline$\Delta i$ & & $\begin{array}{l}0.009 \\
(.836)\end{array}$ & $\begin{array}{l}0.232 \\
(.000)\end{array}$ & $\begin{array}{l}0.039 \\
(.000)\end{array}$ \\
\hline$\Delta \pi$ & & 0 & 0 & $\begin{array}{l}.028 \\
(.001)\end{array}$ \\
\hline$\Delta y$ & & $\begin{array}{l}-0.875 \\
(.001)\end{array}$ & $\begin{array}{l}-0.098 \\
(.743)\end{array}$ & $\begin{array}{l}-0.125 \\
(.001)\end{array}$ \\
\hline
\end{tabular}

\section{United Kingdom}

\begin{tabular}{|c|c|c|c|c|}
\hline response of & to: & $i_{t-1}$ & $\pi_{t-1}$ & $y_{t-1}$ \\
\hline$\Delta i$ & & $\begin{array}{l}-0.085 \\
(.029)\end{array}$ & $\begin{array}{l}0.067 \\
(.0 .016\end{array}$ & $\begin{array}{l}0.025 \\
(.006\end{array}$ \\
\hline$\Delta \pi$ & & 0 & 0 & $\begin{array}{l}.048 \\
(.061)\end{array}$ \\
\hline$\Delta y$ & & $\begin{array}{l}-0.155 \\
(.385)\end{array}$ & $\begin{array}{l}-0.431 \\
(.001)\end{array}$ & $\begin{array}{l}-0.208 \\
(.000)\end{array}$ \\
\hline
\end{tabular}


Table 5. Implied "Taylor Rule" Parameters for Germany and the United Kingdom (p-values in parentheses)

\begin{tabular}{|l|l|l|}
\hline & $\begin{array}{l}\tau\left(\equiv-\gamma_{12} / \gamma_{11}\right) \\
(\text { Long-run Response of Interest Rates to } \\
\text { Inflation })\end{array}$ & $\begin{array}{l}\sigma\left(\equiv-\gamma_{13} / \gamma_{11}\right. \\
(\text { Long-run Response of Interest Rates to } \\
\text { Output })\end{array}$ \\
\hline Germany & $\begin{array}{l}1.026 \\
(0.01)\end{array}$ & $\begin{array}{l}0.056 \\
(0.20)\end{array}$ \\
\hline UK & $\begin{array}{l}0.789 \\
(0.032)\end{array}$ & $\begin{array}{l}0.293 \\
(0.093)\end{array}$ \\
\hline
\end{tabular}

Table 6. Estimates of B (Contemporaneous Responses Derived from Covariance Matrix of Reduced Form System, P-values in parentheses):

\section{Germany}

\begin{tabular}{|l|l|l|l|l|}
\hline response of & to: & $\Delta i$ & $\Delta \pi$ & $\Delta y$ \\
\hline$\Delta i$ & 1 & $\begin{array}{l}-0.159 \\
(0.001)\end{array}$ & $\begin{array}{l}-0.022 \\
(0.059)\end{array}$ \\
\hline$\Delta \pi$ & & 1 & $\begin{array}{l}0.024 \\
(0.261)\end{array}$ \\
\hline$\Delta y$ & & & 1 \\
\hline
\end{tabular}

\section{United States}

\begin{tabular}{|l|l|l|l|l|}
\hline response of & to: & $\Delta i$ & $\Delta \pi$ & $\Delta y$ \\
\hline$\Delta i$ & 1 & $\begin{array}{l}-0.109 \\
(0.066)\end{array}$ & $\begin{array}{l}-0.118 \\
(0.000)\end{array}$ \\
\hline$\Delta \pi$ & & 1 & $\begin{array}{l}0.031 \\
(0.167)\end{array}$ \\
\hline$\Delta y$ & & & 1 \\
\hline
\end{tabular}

\section{United Kingdom}

\begin{tabular}{|l|l|l|l|l|}
\hline response of & to: & $\Delta i$ & $\Delta \pi$ & $\Delta y$ \\
\hline$\Delta i$ & 1 & $\begin{array}{l}-.013 \\
(0.620)\end{array}$ & $\begin{array}{l}-0.048 \\
(0.015\end{array}$ \\
\hline$\Delta \pi$ & & 1 & $\begin{array}{l}0.009 \\
(0.989)\end{array}$ \\
\hline$\Delta y$ & & & 1 \\
\hline
\end{tabular}

Note to Table 6: the sign convention of the specification in (7) implies that a negative coefficient represents a positive contemporaneous response. 


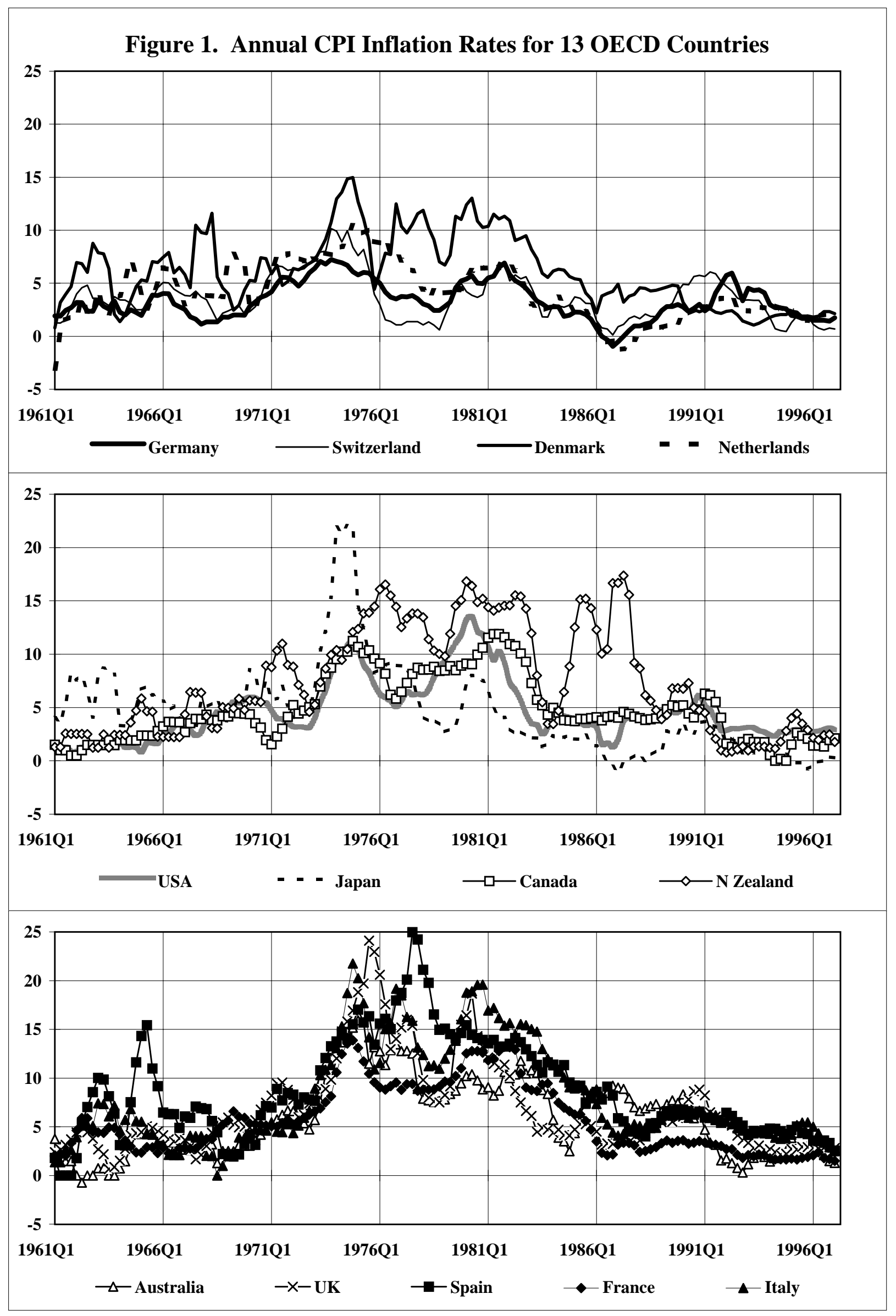


Figure 2. Indicators of Long-Horizon Inflation Uncertainty in 13 OECD Countries

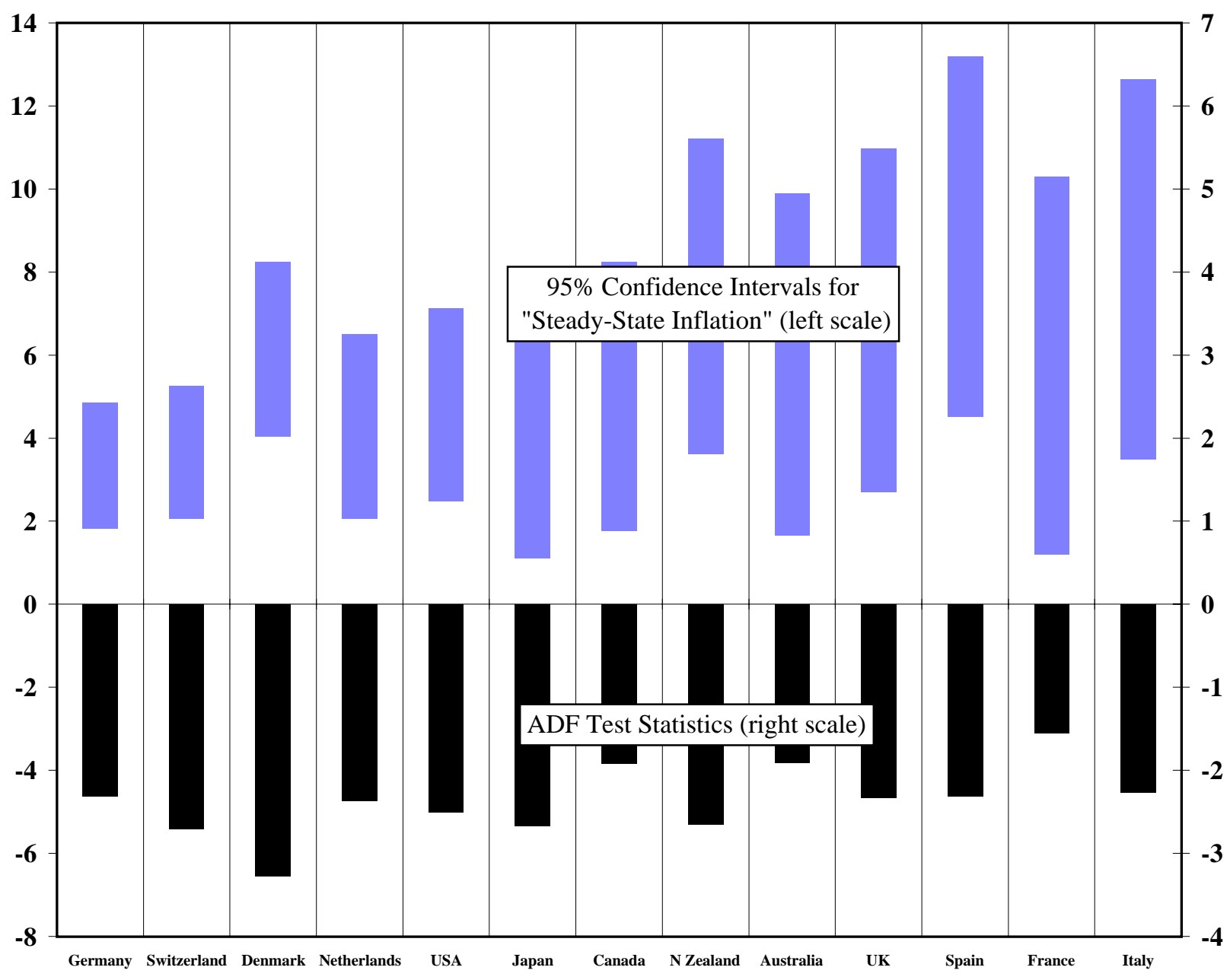


Figure 3. Short- and Long-Horizon Inflation Uncertainty

(Width of 95\% Confidence Interval in Predicting Inflation One Quarter Ahead)

Figure 4. Impact of the Taylor Rule Parameter on an Ad-hoc Policy Loss Function

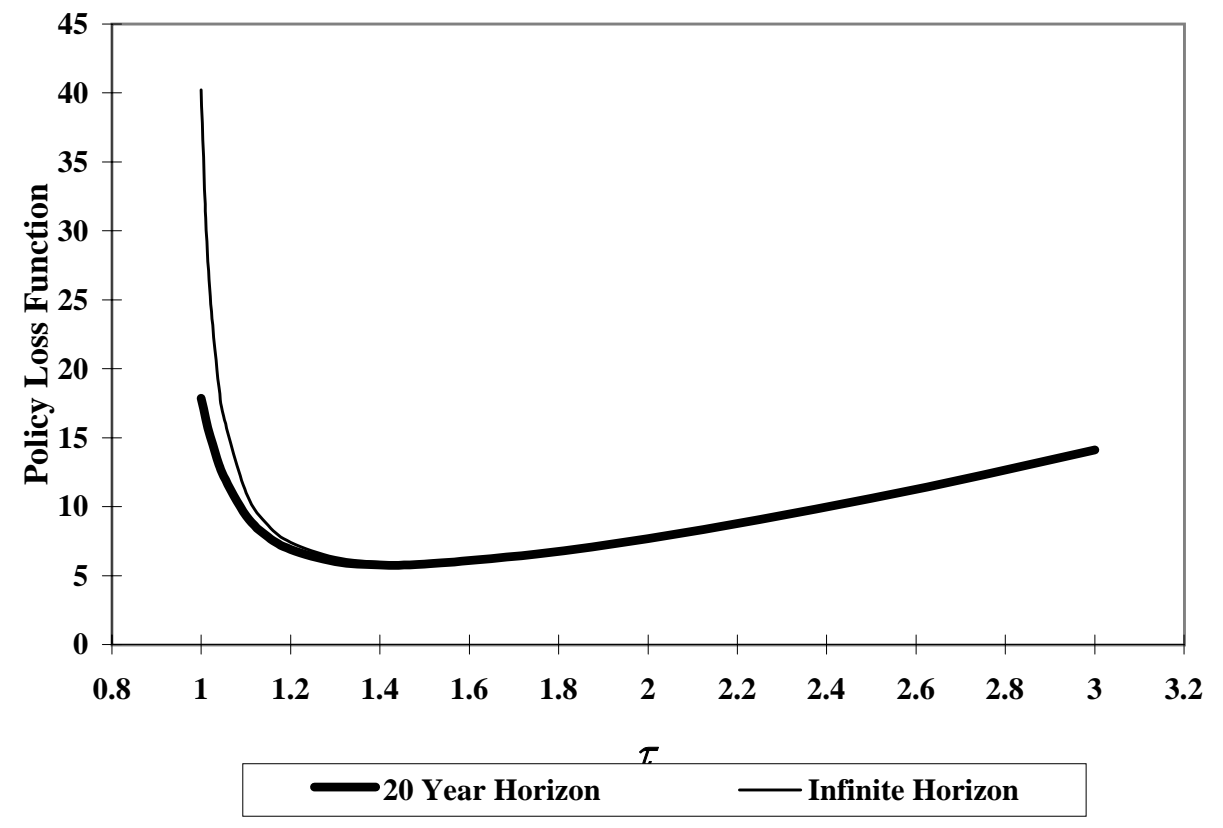




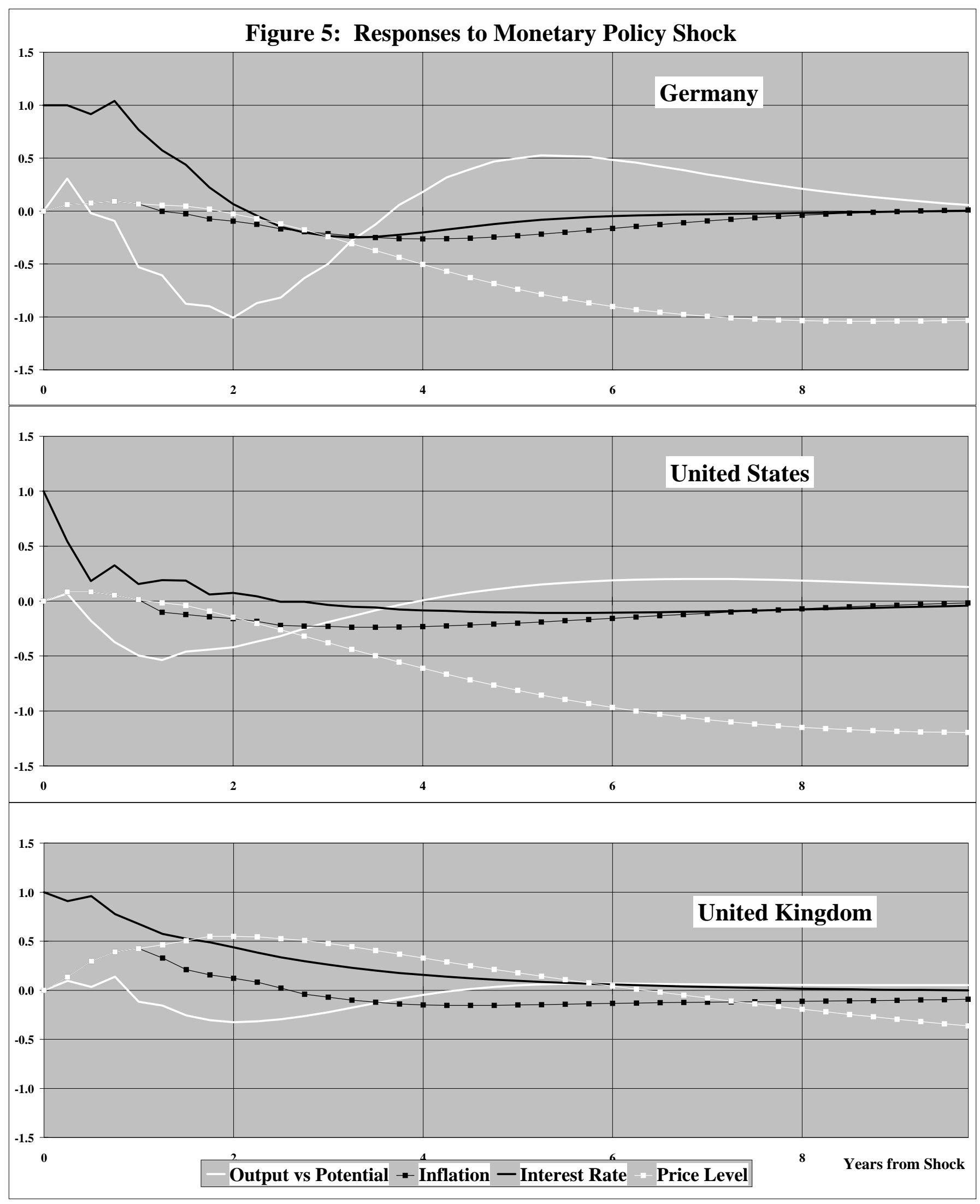




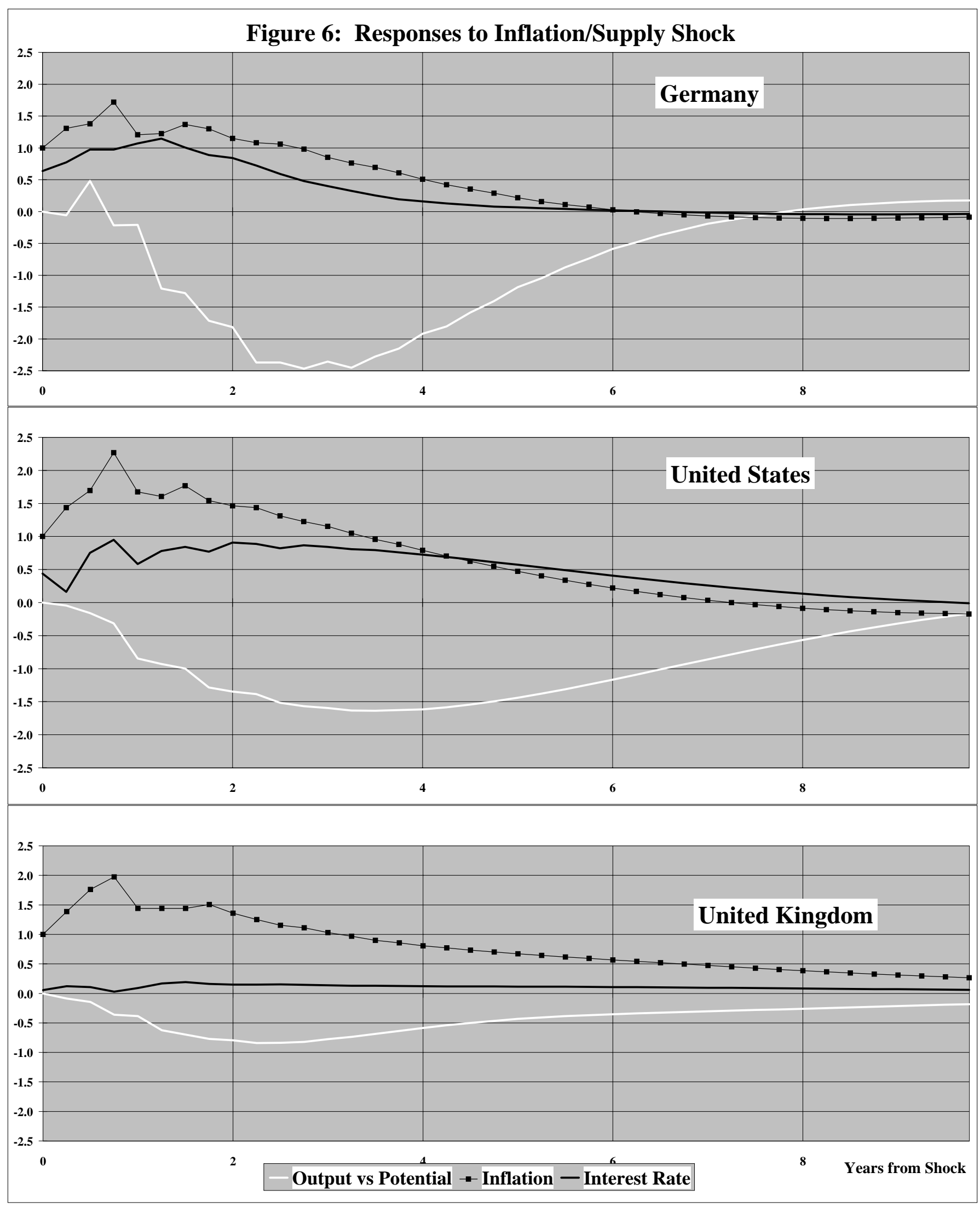




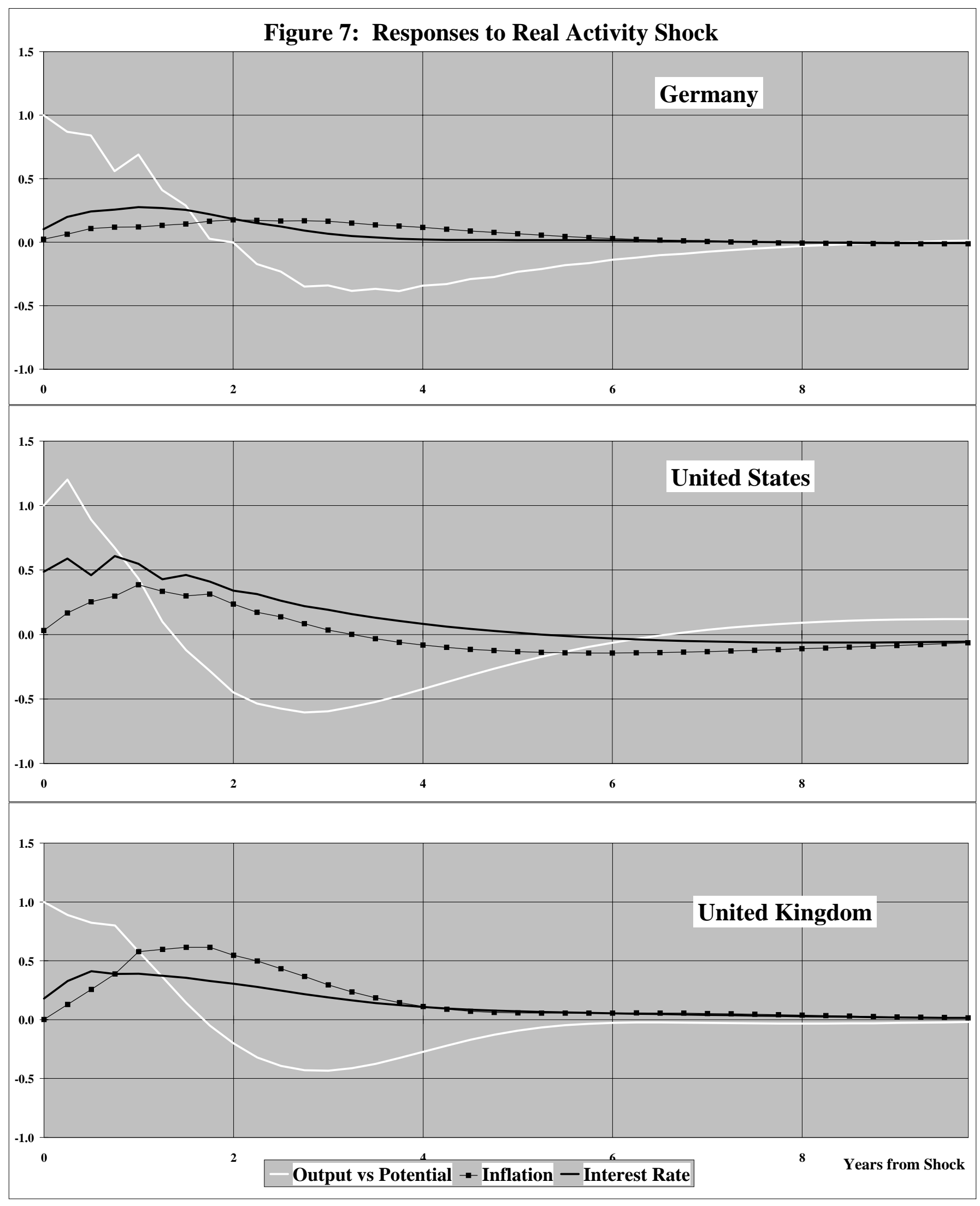


Figure 8. Long-Horizon Inflation Uncertainty and Nominal Interest Rate Effects on Activity (P-Values)

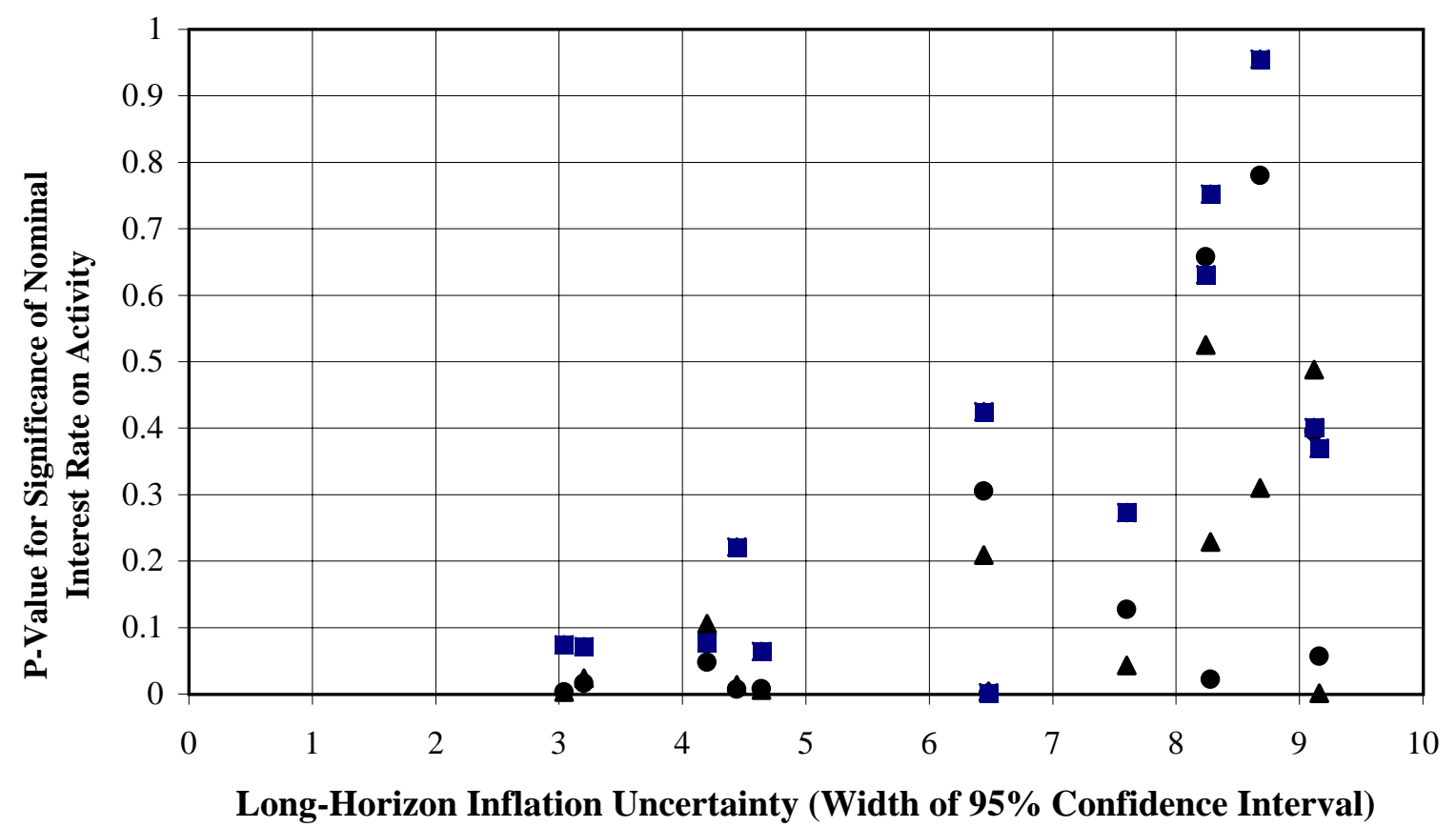

- From regression of activity on lagged nominal rates

$\Delta$ From regression of activity on lagged nominal and real rates

- From regression of activity on lagged nominal rates and inflation 